\title{
Hongshan Households and Communities in Neolithic Northeastern China
}

\author{
Robert D. Drennan ${ }^{a, *}$, Christian E. Peterson ${ }^{b}$, Xueming Lu (吕学明 ${ }^{c}$, and Tao Li (李涛) ${ }^{a, d}$ \\ a Center for Comparative Archaeology, Department of Anthropology, 3302 WWPH, \\ University of Pittsburgh, Pittsburgh, PA 15260, USA \\ ${ }^{\mathrm{b}}$ Department of Anthropology, University of Hawai'i at Mānoa, 2424 Maile Way, \\ Saunders Hall 346 Honolulu, HI 96822, USA \\ ' School of History, Renmin University of China, 59 Zhongguancun Street, \\ Haidian District, Beijing 100872, People's Republic of China \\ ' Present address: Max Planck Institute for the Science of Human History, \\ Kahlaische Strasse 10, 07745 Jena, Germany \\ *Corresponding author, E-mail address: drennan@pitt.edu
}




\begin{abstract}
Analysis of a large sample of household artifact assemblages from residential zones dating to the Hongshan period (4500-3000 BCE) in northeastern China complements regional-scale settlement study and excavation of house structures, platforms, and tombs. Prestige differentiation between household units is recognizable but modest. Productive differentiation is also present, indicating a very small degree of economic interdependence between households involving the utilitarian goods of daily life. Exchange did transcend both local and regional-scale communities, but movement of goods seldom exceeded a few kilometers. Standards of living were similar across households, with no sign of wealth differentiation. Confirming what has previously been suggested about the role of belief systems in Hongshan social integration, the strongest differentiation detectable in the household evidence involved religious roles and ritual activities. The elaboration of ceremonial architecture and funerary ritual of the Hongshan core zone is thus seen not to correspond to larger regional-scale communities, greater projection of political power, a more specialized economy, larger-scale exchange of goods, or accumulation of wealth. These commonly imagined aspects of early complex society were strikingly underdeveloped in Hongshan society, given its complex ceremonial architecture, elaborate burial treatment of presumed ritual specialists, and famous jade carvings.
\end{abstract}

\title{
Keywords
}

chiefdoms, complex society, household archaeology, differentiation, specialization, economic interdependence, prestige, wealth, ritual 
Archaeologists can sometimes be quick to attach labels like early complex society, chiefdom, rank society, or middle-range society to contexts with conspicuously elaborate burials and monumental architecture or other public works. It is often assumed that burials of special people and the organization of labor for communal construction automatically form a package with political integration under powerful leaders, specialized production, economic control, accumulation of wealth, and other features of social complexity. Perhaps because of a deeply ingrained heritage from unilineal cultural evolutionary approaches of the mid-twentieth century, the relationships among the several elements of this package are sometimes so taken for granted that the mere presence of archaeologically conspicuous burials and public works leads researchers to infer the presence of all the other elements even when direct evidence for them is nonexistent. If we think that the relationships between these elements might vary in different settings and we want to investigate this variation, then this procedure clearly will not do-it assumes that the relationships are invariant. Highly elaborate burials almost certainly do indicate individuals who were especially important in their communities. In similar fashion, public works of much scale indicate organized collective labor. Abundant empirical evidence shows, however, that these two aspects of early complex societies do not always correspond to much in the way of political integration, powerful leadership, wealth differences, economic control, specialized production, or other forms of asymmetrical relationships. Much is to be learned about social dynamics by investigating which of these elements combine (and how they combine) in different trajectories of early complex society development (Drennan and Peterson 2006, 2012; Peterson and Drennan 2012). Pursuit of such investigations requires careful attention in each case to separate and direct archaeological evidence for the different elements of the supposed package.

Archaeology can make an especially direct approach to the dynamics of social change in the past by studying the relationships between the households that make up local communities. This set of relationships is the matrix of interaction in which human agents act. It is the arena in which they may find ways to cooperate toward common objectives; it is the arena in which they may come into conflict when the aims they pursue seem to interfere with each other; and it is the arena in which human relationships may become strongly asymmetrical leading, in some cases, to dramatic inequalities of several different kinds (Drennan et al. 2010). For early complex societies this matrix of interaction is the set of social relationships that most often comprise a village-a spatial cluster of households set off from others, probably sharing some sense of cultural identity and certainly (given the constraints of transportation and communication in the ancient past) interacting more intensively with each other than with the members of households in other more distant villages. The elements of the imagined unified package of complex society characteristics are often thought to grow together naturally from the social context provided by "the Neolithic village." And local village communities are indeed a particularly important focus for understanding the emergence and development of the earliest complex societies because the growth of local communities, change in the patterns of human relationships within them, and the establishment of stronger integration with neighboring local communities to form regional entities are the very essence of complex society development.

\section{Hongshan Villages and Supra-local Communities}

$$
\begin{aligned}
& * * * * * \text { INSERT FIGURE } 1 \text { ABOUT HERE***** } \\
& * * * * * \text { INSERT FIGURE } 2 \text { ABOUT HERE***** }
\end{aligned}
$$

The Neolithic Hongshan period in northeastern China (ca. 4500-3000 BCE) provides an opportunity to approach such a transition from the perspective of relationships between households in local communities. Hongshan villages are known from several excavated sites (summarized by Peterson and Lu [2013] and Peterson et al. [2014a:39-41]). The most completely exposed is Baiyinchanghan (Figure 1). By global comparative standards, Baiyinchanghan is a relatively dispersed village community with 17 structures in two groups, each arranged around an open plaza, with associated storage pits of various kinds, rectangular graves, and other features scattered across 4.5 ha (Neimenggu 2004). The typical Hongshan house plan is rectangular, with a floor $50 \mathrm{~cm}$ or more below ground level, an entry ramp up to ground level on one side, and a central hearth (Figure 2). A timber-frame superstructure was enclosed in wattle and daub and supported a thatch roof. Most houses are between 20 and $30 \mathrm{~m}^{2}$; they are regularly interpreted as nuclear family residences whose shelter would have been needed in the fairly 
harsh temperature extremes of both winter and summer. Earlier house structures were larger-often $50-$ $80 \mathrm{~m}^{2}$ in Xinglongwa times (6000-5250 BCE) and over $30 \mathrm{~m}^{2}$ in Zhaobaogou times (5250-4500 BCE). The smaller Hongshan houses might be interpreted as a decline in prosperity or standards of living. At least two Hongshan sites have a single much larger structure, as at Xishuiquan (Figure 2), where one of the three structures excavated covers about $100 \mathrm{~m}^{2}$ (Zhongguo 1982). The largest structure at Baiyinchanghan is not completely preserved, but is spatially set apart from the other structures at the site (Neimenggu 2004). Most structures have no associated storage pits, but over one-third of the storage capacity of the settlement is highly visible and publicly accessible in the area around this larger structure. Artifact samples associated with structures are small and consist of relatively complete artifacts from floors and pits rather than fragmentary artifacts screened from midden deposits, but artifacts related to craft work and storage seem especially abundant at the larger structure, whereas food production and preparation tools are more abundant elsewhere. The proportions of decorated ceramics and serving vessels are relatively low at the larger structure, and higher proportions of fine-paste pottery occur at several other structures. For these reasons the larger structures are not likely to be elite residences; they are usually interpreted as places for collective activities in which all the residents of the local community participated.

Artifacts and ecofacts from excavations document cultivation of millet and other cereals, gathering of acorns and other plants, pig husbandry, and hunting deer and other species. Phytoliths and starch grains from residues on 12 Hongshan grinding stones from Baiyinchanghan support this account (Liu et al. 2016), although the rice starch grains on one grinding stone seem more likely a result of contamination than either cultivation or import. Hongshan villagers also made pottery and stone tools, spun thread, wove cloth, worked leather, and made ornaments of shell and stone. Production of these goods is usually thought to be organized at the household level. Some suggest craft specialization, especially for elaborate ceremonial items of carved stone and pottery, on the basis of their elaborateness and the supposed difficulty of making them, but very little direct evidence of productive organization has been reported. Altogether 19 burials from the occupations at Nantaizi and Baiyinchanghan suggest modest social differentiation. Some are simple interments in pit graves with no offerings. The most elaborate had three ceramic vessels, two flaked stone tools, a stone shovel, a stone axe, a quern and roller, and three bone tools interred with four individuals in a single grave (Neimenggu 1994); another had a pair of jade earrings, a stone chisel, and shells in the hand of the lone individual.

Hongshan villages were usually quite small. Not surprisingly, those chosen for excavation seem among the larger and more nucleated. Baiyinchanghan's population might be estimated at around 50100 people, allowing 3-6 per house (somewhat small for nuclear families but a figure often used for Hongshan houses since they are rather small). Comprehensive regional-scale settlement research has been carried out for two survey areas within the Hongshan culture area: Chifeng and the Upper Daling valley (Chifeng 2011a, 2011b; Peterson et al. 2010, 2014a, 2014b). In the Upper Daling valley 87\% of Hongshan local communities had fewer than 5-10 inhabitants and were thus not villages at all but scattered homesteads. Eight local communities $(6 \%)$ had populations estimated in the general size range of Baiyinchanghan or larger (more than 30-60 and up to the largest at 250-500 inhabitants). Although these larger local communities were few in number, about three-fourths of the Upper Daling valley's population did live in them, so village living was the most common pattern for Hongshan people. Results from the Chifeng region are similar, and most other known Hongshan settlements fit this description, although there are a few apparent contradictions to the pattern as well.

At Weijiawopu (Figure 1), coring across 9.3 ha suggests houses in an area of 4.6 ha (Cao 2010; Duan et al. 2011). Of the 4.6 ha, about one-fourth (1.2 ha) has been completely excavated, exposing 78 houses. A similarly dense occupation in the remaining three-fourths would amount to a total of around 300 houses and a population of perhaps 900-1800. If true this would make Weijiawopu a much larger and much more nucleated village than other known Hongshan villages. As usual, however, when estimating populations of large settlements by counting houses, it is difficult to judge just how many of the houses were occupied contemporaneously. The house floors seem to group into three sets at different depths below the modern ground surface, perhaps indicating a chronological distribution. If only around one-third of the houses at Weijiawopu were occupied at the same time, then its population would be comparable to the larger villages known elsewhere. 
Several sites known only from their surface remains have also been described as very large compact villages. At these sites, presumed house locations are observable on the surface as patches of dark soil 4-6 $\mathrm{m}$ across. Occasionally such a patch has been cut across by agricultural terracing or erosion, making it possible to observe the deposits below in a cut bank, where an unmistakable house floor can sometimes be seen. At Duliyingzi (Aohan 2009) and at sites 6375, 6384, X11, and others in the Lower Bang valley (Zhongguo and Neimenggu 2005) these dark patches have been mapped as circles in fairly regular rows at quite close spacing, contrasting with the more dispersed character of most excavated villages but perhaps consistent with the most compact habitation areas known from systematic regional settlement analysis. Densities at Duliyingzi and Site 6375 are 19 and 16 houses/ha, respectivelycomparable to Weijiawopu at 17 houses/ha even if all were occupied contemporaneously. Densities as high as 20 houses/ha can be estimated in the Upper Daling valley (see below), but only in very small patches (around $0.5 \mathrm{ha}$ ) within larger more dispersed villages. In contrast, such densities cover the entire settlements mentioned above, ranging up to 6.7 ha. At Site X11, 22 dark circles in 0.6 ha would yield a density of 37 houses/ha, and at Site 6384, 52 dark circles are packed into a single patch of less than 0.5 ha in the center of the site, for an astounding density of over 104 houses/ha.

The largest total population based on such house counts would be 300-600, consistent with the largest local communities estimated from regional settlement analysis, but the higher degrees of nucleation implied across fairly large areas at some of the sites where dark circles are mapped would be exceptional when compared either to sites where degree of nucleation is determined from artifact densities or to those that have been excavated. The authors' first-hand observations at Duliyingzi and Lower Bang sites 6375, 6384, and X11 is that surface artifact densities are quite low by comparison with those recorded in Chifeng and the Upper Daling valley, where the most nucleated patches within Hongshan villages can reach surface densities of $1-2$ sherds $/ \mathrm{m}^{2}$ averaged across areas of 0.25 ha or so (that is, not counting small hot spots of higher density). Surface densities at Duliyingzi and Lower Bang sites 6375,6384 , and X11 are perhaps two orders of magnitude lower-in the neighborhood of 0.01-0.02 sherds $/ \mathrm{m}^{2}$. It cannot be that Hongshan artifacts at these latter sites are more deeply buried and thus invisible, or the dark circles would be also. The conclusion seems inescapable that the dark circles mapped at these sites cannot all represent contemporaneously occupied houses, or there would be denser accumulations of sherds. Thus both total Hongshan populations and residential densities were much lower than just counting circles would suggest-well within the range for villages known from regional settlement study in Chifeng and the Upper Daling valley, and in fact in the lower part of that range.

At a larger, regional scale, settlement analysis for Chifeng (Chifeng 2011a, 2011b) and the Upper Daling valley (Peterson et al. 2010, 2014a, 2014b) shows repetitive clusters of Hongshan occupation, each a few (4-8) kilometers across. Mostly they contain a few hundred (200-500) inhabitants; one stands out slightly in demographic terms with an estimated 450-900 inhabitants. Often a particularly large village or two or three somewhat smaller ones close together form the demographic center of these settlement clusters, which have been interpreted as the earliest identifiable integrated regional social entities in northeastern China. Ritual and ceremonial activities have been seen by many scholars as the principal integrative forces in Hongshan societies (e.g. Guo 1995; Nelson 1996; Li 2008). The most conspicuous and famous archaeological remains of Hongshan societies are circular or square stone-faced platforms, often incorporating burials with offerings consisting largely of jade elaborately carved in apparently symbolic forms (summarized by Peterson and Lu 2013:56-61). These platforms are commonly interpreted as ceremonial in function and the obviously important individuals buried in them as Hongshan leaders or rulers.

Although this general view of Hongshan politics and leadership based strongly on ritual and ceremony is widely agreed to, it conflicts with the view, also frequently expressed in the literature (e.g. Li 2004; Zhang et al. 2013) that Hongshan sites can be divided into two mutually exclusive typesceremonial and habitation-and that the two are not spatially associated since excavated habitation sites have not included platforms with elaborate burials, and excavation of platforms has seldom extended far beyond them to document possible residential zones. Analysis of the distribution of ritual facilities and their relationship to population clusters in the Upper Daling valley, however, demonstrates that ceremonial platforms tend to occupy central locations in regional-scale clusters of occupation, just as 
would be expected if the activities that took place at them contributed importantly to the centripetal forces drawing settlement together into clusters (Peterson et al. 2014a:49-69). Sometimes the platforms are right in the midst of substantial zones of residence, sometimes slightly set off from them, but they are regularly central within the regional-scale clusters. This regional-scale connection between ceremonial architecture and habitation easily escapes notice since most excavated ceremonial sites are not in zones where comprehensive regional settlement research has been carried out. The Upper Daling valley is an exception in this regard since the excavated major ceremonial structures at Dongshanzui (Guo and Zhang 1984) are within the Upper Daling survey area. By far the largest concentration of Hongshan ceremonial architecture and burials is at Niuheliang. It includes the most impressive known examples, with several unique features, scattered across 20 or more specific localities, a number of which have been extensively excavated (Liaoning 2012). Excavations tightly focused on public architecture have exposed little in the way of residential remains, giving the impression that little or no settlement was associated with them. Systematic regional settlement study in 2014, however, has conclusively documented even higher population densities in the area around these monuments than in either the Chifeng or Upper Daling regions. The Niuheliang monument group does appear to be something quite different from the usual supra-local communities, but the association between public architecture and habitation at a regional scale is incontestable (Liaoning and Zhongguo 2015; Drennan et al. 2017).

Other evidence is more complicated. The Hongshan ceremonial architecture known for the Chifeng region all occupies the same kind of central location in regional settlement clusters seen in the Upper Daling valley, but only 5 of some 14 regional-scale communities of reasonable size show surface evidence of ceremonial facilities. The absence of evidence of ceremonial architecture is especially concentrated in the southern part of the Chifeng survey area, where subsequent occupation and land use have been particularly intensive, so it is possible that this has erased surface evidence of ceremonial structures (although this has not occurred under generally similar conditions in the Upper Daling valley). Fair-sized platforms occur in the Upper Laohushan valley (Zhongguo and Neimenggu 2005) associated with low-density artifact scatters that resemble the surface evidence of Hongshan occupation in Chifeng. Habitation remains are documented for the Lower Bang valley, even if the local communities seem smaller and less nucleated than the number of dark circles would make it seem (see above), but in a region where conditions would make remains of public architecture fairly conspicuous, platforms have not been found (Zhongguo and Neimenggu 2005). When and where they occur, then, ceremonial platforms seem located for an important role in Hongshan daily life, but in the southern part of the Chifeng region and the Lower Bang valley, evidence of public architecture is curiously scarce, a point to which we will return below.

At a yet larger macro-regional scale including the entire Hongshan culture area, another distributional pattern of Hongshan ceremonial architecture and elaborate burials emerges. A substantial majority of the largest and most impressive ceremonial structures, as well as the most elaborate burials with the finest carved jades, occurs in what we have referred to as the Hongshan "core zone" (Peterson et al. 2010; Drennan et al. 2014; Peterson et al. 2014a) - a band some $150 \mathrm{~km}$ long and $50 \mathrm{~km}$ wide (Figure 1). At one end is the unique concentration of platforms and burials at Niuheliang, separated by 25 $\mathrm{km}$ from another especially impressive excavated ceremonial complex at Dongshanzui (in the Upper Daling valley). At the other is an architecturally elaborate tomb with carved jade birds and jewelry at Hutougou. In between are the Upper Laohushan valley with an excavated trapezoidal platform at Caomaoshan and at least five platforms at other sites, a recently excavated elaborate tomb within a platform near Chaoyang, and a generally much higher density of more impressive ceremonial architecture than occurs outside this core zone.

It is quite clear that the entire Hongshan culture macro-region of some $250,000 \mathrm{~km}^{2}$ was not integrated into a single polity, although Niuheliang may have played an especially important role in establishing and maintaining cultural and ideological identity across this large region, perhaps as a pilgrimage center (Drennan et al. 2017). But the artistic and architectural manifestations of Hongshan culture are by far most elaborately developed in a core zone that includes Niuheliang. We hasten to add that we do not use the terms "core" and "periphery" to imply anything like a world systems model. But the artistic and architectural achievements of what we refer to as the Hongshan core are generally assumed to correspond to a greater elaboration of ritual and ceremonial activity, and it is tempting to 
think of presumed leaders buried in much more impressive ways in the core zone as wielding greater power and/or accumulating greater wealth than those of the Hongshan periphery. One can imagine that they ruled over larger polities whose populations could more easily marshal the resources for large public works projects and the sustenance of elites than those of the periphery. Results of the Upper Daling valley regional-scale settlement study around Dongshanzui in the core zone, however, indicate that overall regional population densities were not higher in the core zone. Nor were local communities markedly larger than those in the peripheral Chifeng region (Peterson et al. 2010, 2014a). Both the spatial and demographic scales of supra-local communities in the Upper Daling valley and Chifeng were also quite similar, so core zone leaders do not seem to have forged larger political entities. The difference between core and periphery, then, does not seem to be larger politically integrated populations that sustained greater artistic and architectural outlay on ceremony.

The local and regional-scale communities of the core zone, though, might have been more prosperous. The core zone might have had a more highly developed economy involving greater productive differentiation (Drennan and Peterson 2012:78-79) and more household economic interdependence in the realm of the practical utilitarian goods of daily life. Wealth and/or prestige differentiation (Drennan and Peterson 2012:76-78) might have been stronger in core zone communities. To be clear, by "wealth" and "prestige" we mean just what the words commonly mean in English: wealth is an abundance of valuable material possessions, and prestige is esteem or respect in the non-economic sphere of social relationships. While the two may well be connected, such that wealth confers prestige (or vice versa), this is not necessarily the case. A clear conceptual distinction between the two principles is required in order to investigate empirically whether they are connected in a particular context or not and, if so, how. Re-labeling prestige differentiation "relational wealth" (e.g. Diwan 2000; Borgerhoff Mulder et al. 2009) only confuses the issue and subliminally undermines the important point that prestige is not per se economic in nature. And these concerns bring us directly back to the issue we opened with above: how interaction between households in local communities changes as the conspicuous archaeological manifestations of complex societies appear and elaborate.

\section{Delineating Household Units}

Collecting the evidence needed to reconstruct patterns of interaction between households in local communities has often been labeled household archaeology. The sketch above of what is already known about Hongshan households and villages results from a long tradition of household archaeology in China, although it has not usually been given that label. Excavation of Hongshan residences has provided an idea of village layout and knowledge of the general nature of structures, pits, burials, and other features, although the sample of excavated features is not large and very little of it pertains to the core zone. These excavations in the Hongshan periphery have also produced artifacts, especially whole or reconstructable pottery vessels and complete or near-complete artifacts of stone, bone, and other materials. Comprehensive recovery of highly fragmented remains from middens and other trash deposits has been less common, and this sharply limits our ability to reconstruct the potentially differing activities, roles, and statuses of different households upon which their interactions are based.

The analysis presented below is based on just such fragmented remains of garbage with the aim of using the artifact assemblages recovered from different household units to assess the degree of differentiation between households in communities of both the Hongshan core and periphery in terms of prestige, production, wealth, and ritual. These assessments of several different kinds of inter-household differentiation, when compared between core and periphery, make it possible to say what kinds of forces were operating more strongly in the core zone and thus might be involved in the apparently more impressive expressions of eliteness, leadership, or power there. We might find, for example, that wealth differentiation (seen as higher proportions of more costly possessions in some household units) was stronger in the core zone and thus potentially the basis of greater power wielded by leaders or elites there. Alternatively, we might find that wealth differentiation was slight and no greater in the core than in the periphery, and thus conclude that it was not accumulation of material wealth that made core zone elites stand out more impressively than those of the periphery.

The remains analyzed below were not recovered from extensive village excavation, but instead from the surface. For many readers this will immediately raise the question of how they can be connected 
to households-or even whether they can be taken to represent household remains at all. The connection between Hongshan village remains and the surface scatters of artifacts visible without excavation is especially well documented in the Upper Daling valley through extensive and intensive surface collection, magnetometry, and test excavation (Peterson et al. 2014a:29-45, 2014b). Magnetometer survey has consistently revealed high densities of magnetic anomalies associated with the surface scatters from which the artifacts whose analysis is reported here were recovered. Test excavation at these sites has confirmed the anthropogenic origin of these magnetic anomalies. In some cases they result from modification of the magnetic properties of the upper soil layers as a product of human occupation. Other magnetic anomalies correspond to such cultural features as pits and architectural arrangements of rocks. The density of the surface artifact scatters regularly increases where magnetometer survey reveals higher densities of anthropogenic anomalies. Both radiocarbon and thermoluminescence dating confirms the assignment of these remains to Hongshan times based on well-documented ceramic styles. The surface remains include fragments of burned daub from structure walls. That the surface scatters represent zones of Hongshan residence with very little in the way of remains from other periods is unequivocal. Our stratigraphic tests are the only excavations ever carried out in these residential zones. Although cultural features are unmistakable in the tests, their remains are so extremely fragmented and poorly preserved that little could be learned about structures and features by excavating them. Even artifact densities taper off very quickly below the plow zone. Very little archaeological evidence of these villages remains, then, except artifacts on the surface and within a few centimeters of the present ground surface. This makes surface collecting not a second-best alternative to extensive excavation but the only way to study these Hongshan villages in the Upper Daling valley. The conversion of these sites into very shallow deposits with few remains of structures and features by the deflation of the loess hills on which they occur has created ideal conditions for the rapid and efficient recovery of very large samples of artifacts representing a large number of separate household units.

$$
* * * * * \text { INSERT FIGURE } 3 \text { ABOUT HERE***** }
$$

The household and local community evidence presented for the first time here results from a multi-scalar research program that began with systematic complete-coverage regional survey (Peterson et al. 2010, 2014a) of $200 \mathrm{~km}^{2}$ in the Upper Daling valley (Figure 3). More intensive work focused on 16 ha of moderate- to high-density occupation documented in the regional survey in three different localities: Dongshanzui (surrounding the excavated ceremonial structures), Sanjia (about $1 \mathrm{~km}$ southwest of the Dongshanzui zone), and Erbuchi (about $5 \mathrm{~km}$ northeast of the Dongshanzui zone). These core zone households and communities are compared to Fushanzhuang, a 35-ha very dispersed Hongshan village documented by systematic complete coverage survey in the Chifeng region (Figure 1) and subsequently studied more intensively (Peterson 2006, 2012; Chifeng 2011b). $* * * * *$ INSERT FIGURE 4 ABOUT HERE*****

At Fushanzhuang, Dongshanzui, Sanjia, and Erbuchi archaeologists walked systematically back and forth across the entire selected areas at 5-m intervals marking all sherds on the surface with pin flags. This was an efficient way to observe directly how the density of surface artifacts varied across the areas studied and select higher-density parts of them for even more intensive investigation (Figure 4). At the dispersed community of Fushanzhuang these higher-density areas themselves were approximately the size of the areas around individual houses at excavated sites. These household-sized clusters of very high-density artifacts have persisted through the millennia since Hongshan times. Their connection with the subsurface structures and features representing a household can be observed at other Hongshan residential sites as well. As noted above, at some sites circles of dark soil visible on the surface indicate individual Hongshan houses (even if not all contemporaneous); these circles have not been erased by millennia of plowing, and their relation to house structures can be confirmed through the exposure of house floors below in cut banks. They are also associated with distinct higher-density clusters of surface artifacts at sites such as Duliyingzi. Dark circles of this sort are occasionally visible at Fushanzhuang when light and vegetation conditions are just right; the artifact hot spots are more conspicuous and consistently observable.

Given the size and spacing of houses at excavated sites and the dimensions of the high-density artifact clusters at Fushanzhuang, it is not possible that the Fushanzhuang clusters represent more than two or three households each, and most of them probably represent single households. At Dongshanzui, 
Sanjia, and Erbuchi the same kind of very high-density artifact clusters occurred-sometimes with dimensions similar to those at Fushanzhuang and to excavated household remains-suggesting that they represented the garbage of one, or perhaps two, households. Other clusters were larger, sometimes considerably larger, representing zones of multiple houses and associated garbage middens at much closer spacing than those at Fushanzhuang.

In all four residential zones, the high-density artifact clusters identified by closely spaced field walking and placing pin flags at artifacts were subjected to intensive surface collection and the recovery of near-surface artifacts by raking up the uppermost $5-10 \mathrm{~cm}$ of soil. Horizontal control was by squares 1 by $1 \mathrm{~m}$ at Fushanzhuang and 5 by $5 \mathrm{~m}$ at Dongshanzui, Sanjia, and Erbuchi. (See Peterson 2006:24-27 for full details of methodology at Fushanzhuang; full methodological detail and complete data for Dongshanzui, Sanjia, and Erbuchi are available online in the Upper Daling Region Community Dataset in the University of Pittsburgh Comparative Archaeology Database <www.cadb. pitt.edu> [Peterson et al. 2017].) Within the larger high-density artifact clusters at Dongshanzui, Sanjia, and Erbuchi, closer examination of the higher-resolution density data from the intensively collected $5-\mathrm{m}$ squares revealed clustering at a yet smaller scale. These smaller artifact clusters did approximate the dimensions and spacing that excavated sites would lead us to expect for single houses with associated garbage middens (or occasionally perhaps two houses close together). Identification of these smaller-scale hot spots within intensively collected areas completed the delineation of the household units that form the cases in the analysis presented below. Full details of this last stage of high-density cluster identification are also available online (Peterson et al. 2017).

Finally the sample of household units totaled 69 (19 from Fushanzhuang, 17 from Dongshanzui, 23 from Sanjia, and 10 from Erbuchi). In no case does this represent all the households in the local community. Fushanzhuang is estimated to have had a total of about 30 households (on average through Hongshan times); Dongshanzui is part of a dispersed local community that might have had as many as 30 households at a given time; Sanjia, as many as 100 households; and Erbuchi, some 16.

\section{Identifying and Comparing Artifact Assemblage Patterns}

\section{$* * * * *$ INSERT TABLE 1 ABOUT HERE*****}

Each of the 69 household units was represented by an artifact assemblage consisting primarily of pottery fragments and lithic tools. Sample sizes ranged from as small as 45 sherds from a household unit at Erbuchi to as many as 5,893 from one at Sanjia and from as few as 6 lithics from a household unit at Erbuchi to as many as 1,313 from one at Fushanzhuang (Peterson et al. 2017). Lithic tools were classified according to widely used morphological types whose form allows at least a broad characterization of function. The counts recorded for various classes of ceramics and lithics and their attributes were converted into a set of ratios, proportions, and means for each household (amounting altogether to 20 variables for ceramics and 39 for lithics). This set of variables was winnowed down to those showing the most interpretable and meaningful variation across household units in a series of exploratory nonmetric multidimensional scaling analyses. The final analyses presented here were based on the variables in Table 1.

Nonmetric multidimensional scaling was the multivariate technique chosen because of its ability to simultaneously represent varied forms of structure in a dataset (clusters, axes of scalar variation, etc.). This matched our expectation that the relationships between household units might be complicated and of varied sorts. The fundamental principles of multidimensional scaling are also readily accessible to common sense and its graphical results easily and intuitively understood (Drennan 2009:285-307). Household units, then, were the cases in the analyses; and characteristics of their artifact assemblages, the variables. Consequently in each of the multidimensional scaling plots, each point represents a household unit. Points that are closest together represent the most strongly similar artifact assemblages; points that are farthest apart, the most strongly differing ones. It turned out to be most meaningful to analyze ceramic and lithic assemblages separately, and the two classes of artifacts seem to be most clearly related to different aspects of relationships between households. Analyzing the assemblages from Fushanzhuang separate from the assemblages of the three residential zones in the Upper Daling valley also turned out to be more meaningful than combining the assemblages from the Hongshan core zone and those from the periphery into a single analysis. 


\title{
Ceramic Assemblages in Upper Daling Communities
}

\author{
$* * * * *$ INSERT FIGURE 5 ABOUT HERE*****
}

A small selected set of variables (the first four in Table 1) encapsulated the most meaningful variation discovered in household ceramic assemblages. The clearest multidimensional scaling result (Figure 5) was produced from standardized Euclidean distances between all pairs of the 50 household units at Dongshanzui, Sanjia, and Erbuchi; the final stress for this two-dimensional configuration was 0.147.

The principle that comes through most strongly in this solution seems connected to asymmetrical relationships between households in terms of social ranking. The four ceramic variables that conjointly produced the patterning in Figure 5 all have to do with the esthetic and/or functional characteristics of ceramic vessels. Most of the household units sampled at Dongshanzui, Sanjia, and Erbuchi are arrayed near the right edge of the configuration. Four household units (105 and 109 from Dongshanzui, 019 from Sanjia and 201 from Erbuchi) pull out strongly from the main group toward the upper, center, and lower left. All have relatively high proportions of fine-paste ceramics; 105 and 201 are also distinguished by high proportions of slipped surfaces; 109 also has especially high proportions of decorated ceramics; and 019 also has especially high proportions of serving vessels. Another six to eight household units pull out to the left of the vertical band near the right edge of the plot, also with relatively high proportions of finepaste ceramics combined in varying ways with relatively high proportions of slipped surfaces, decoration, and serving vessels. A high proportion of fine-paste pottery is consistently the main factor that moves household units toward the more prestigious (left) side of the plot, and when this combines with high proportions of one or more of the other variables, units are pulled more strongly to the left and upward or downward. Even among the main group of household units there is some separation with regard to these ceramic attributes, with moderately high proportions of decoration (in the upper right quadrant of the plot) found especially in a good many household units at Sanjia and Erbuchi and moderately high proportions of serving vessels (in the lower right quadrant of the plot) found especially in a good many household units from Dongshanzui.

A few household units then at Dongshanzui, Sanjia, and Erbuchi have, in varying ways, higherquality pottery assemblages than most household units do. They would have been in better position than others to enjoy the esthetic and practical benefits of slipped surfaces, fine paste, and decoration and/or to have a larger inventory of vessels for serving and more elegant presentation of food. These characteristics of pottery assemblages have often been related by archaeologists to prestige differentiation. There is also potentially a connection to wealth differentiation since pottery with these characteristics is more costly to produce in terms of labor investment. In the case of Hongshan utilitarian household pottery, however, the increase in labor cost that goes with slipped surfaces, decoration, and fine paste is minimal. Other kinds of artifacts that are costly to produce are absent, not only from our surface collections in residential zones, but also from excavations of residential zones at other sites where excavations have been carried out. The use of higher quality pottery by the members of these household units thus seems a question less of accumulating the resources to afford a "luxury" than of displaying social refinement, perhaps in contexts of social consumption of food ("feasting") where household prestige can be enhanced. These differences thus amount to "functional" differences between household units since different balances of social activities are involved. The fact that higher proportions of these four variables combine in different ways to pull some household units out of the main group in the scaling configuration suggests that household units with greater social prestige displayed (and perhaps enhanced) that prestige through social behaviors that varied somewhat from household to household.

\section{Ceramic Assemblages at Fushanzhuang \\ $* * * * *$ INSERT FIGURE 6 ABOUT HERE*****}

The clearest multidimensional scaling result for the household units at Fushanzhuang (Figure 6) was produced in exactly the same way: from standardized Euclidean distances between all pairs of the 19 household units at Fushanzhuang; the final stress for this two-dimensional configuration was 0.052 .

Again the dominant principle involves asymmetrical relationships between households. This time the majority of the household units group toward the upper right of the plot. Fine paste proportions are generally lower at Fushanzhuang than at the Upper Daling residential zones, and high proportions of fine 
paste play a more varied role in delineating what again appears to represent prestige differentiation. Two household units (F01 and F13B) are separated strongly from the main cluster toward the left, one much more strongly than the other. Two others (F03 and F06) are strongly set off toward the bottom of the plot. It is high proportions of decoration and slipped surfaces that distinguish the former two, while the latter two have high proportions of fine paste and serving vessels. A fifth household (F13A) is somewhat removed from the main group toward the center left of the plot with a combination of all four characteristics.

The Fushanzhuang analysis thus leads to conclusions similar to those arrived at for the Upper Daling communities. Ceramics are an archaeologically visible indicator of what appear to be modest differences in social prestige between household units. The use of pottery may also have been among the ways in which this social prestige was reinforced and enhanced in the social matrix of Hongshan villages. In the Fushanzhuang scaling, there appears to be a sharp distinction between the use of fine paste pottery and serving and presentation of food on the one hand and the use of more elaborate decorated and slipped pottery on the other. We have previously used this observation to suggest two distinct sets of behaviors involved in social prestige. Such a distinction is less clear in the Upper Daling analysis and may be to a large extent a product of the fact that the Fushanzhuang analysis represents only 19 households from a single residential zone whereas the Upper Daling analysis represents 50 households from three residential zones and thus reflects a more varied set of higher-prestige households with more subtle gradations of behavior between these two contrasting emphases.

Neither at Fushanzhuang nor in the Upper Daling communities does the prestige differentiation that is indicated create sharp divisions between clearly defined groups of high- and low-ranking household units. It forms, instead, an axis of gradual variation. The median Euclidean distance between pairs of household units at Dongshanzui, Sanjia, and Erbuchi is 2.510 (with an error range for 95\% confidence of 2.425-2.507); for Fushanzhuang it is 2.034 (1.809-2.397). The samples of households from the Upper Daling valley and from Fushanzhuang are thus large enough to give us high statistical confidence that the differences between household ceramic assemblages are greater in the core zone than in the periphery, but those differences are not very much greater in the core zone. In sum, then, prestige differentiation as indicated by these ceramic variables is modestly stronger in the core zone than in the periphery.

\section{Lithic Assemblages in Upper Daling Communities \\ $* * * * *$ INSERT FIGURE 7 ABOUT HERE*****}

Of a larger number experimented with, a selected set of 19 lithic variables produced the clearest patterning of variation in lithic assemblages between households (Table 1). The most interpretable multidimensional scaling result (Figure 7) was produced from standardized Euclidean distances between all pairs of the 50 household units at Dongshanzui, Sanjia, and Erbuchi; three dimensions were required for an acceptably good representation of the data, and the final stress for this three-dimensional configuration was 0.142 . Since the samples of lithic artifacts from some household units were quite small, care was taken to ensure that in no instance were the patterns described here dependent solely or even largely on the positions in the scaling configuration of household units represented by fewer than 50 lithic artifacts.

Not surprisingly, the patterning in the lithic assemblages is considerably more complicated than in the ceramic assemblages. In the plot of dimensions 1 and 2, most of the household units fall in a fairly tight cluster in the center right portion of the plot. These household units have high proportions of unifacial scrapers, complete flakes, retouched flakes, and indicators of lithic reduction. Their lithic assemblages indicate generalized light duty cutting and scraping activities, and the fact that this description fits such a large number of highly similar household lithic assemblages suggests that this mixed light duty tool set represents a normal range of ordinary basic household activities.

Adzes/axes and other ground stone tools are also well represented in this cluster, with especially high proportions toward the left side. The field clearance and cultivation indicated by this agriculture/woodworking tool set is also an obvious component of ordinary activities for most household units. With especially high proportions of these tools, Household Unit 018 at the far left of the plot might 
be a special locus for woodworking. The household units at the left side of the main cluster also have high proportions of flake cores and shatter, characteristic of late-stage lithic reduction.

Below the main cluster in dimensions 1 and 2 lies another more diffuse cluster in which most household assemblages have medium to high proportions of retouched flakes, artifacts with obtuse edge angles, and projectile points combined with relatively low proportions of choppers. Hunting and heavy scraping and chopping (perhaps hide processing) may be the activities especially strongly represented in these household units.

Beginning in this last cluster and extending downward to Household Unit 001 is a trend toward increasing proportions of blade cores and thus blade production. (Household Unit 001 cannot be confidently identified as especially strongly specialized in blade production, though, because its sample of lithics is very small.) The presence of these higher proportions of blade cores within the cluster representing hunting, heavy scraping, and chopping may suggest that these latter activities were particularly connected with blade production. This axis corresponds to another vertical axis of variation in the dimensions 1 and 2 plot, with proportions of good lithic raw material increasing from top to bottom.

At the top of the dimensions 1 and 2 plot, where the last-described axis begins are several overlapping small groups of household units with high proportions of abraders, awls/drills, and fine-edged choppers. These tools could be used in a variety of activities, but their association in this small set of households could represent miscellaneous craft production of various kinds, such as making tools or ornaments of ground stone or bone.

Looking at dimensions 1 and 3 together adds detail to the basic picture from dimensions 1 and 2 . Early-stage lithic reduction is more clearly separated here from late-stage reduction. Toward the top of the plot are household units with high proportions of blades and tools with especially acute edge angles, both reflecting tools for fine cutting.

Likewise the plot of dimensions 2 and 3 helps to clarify and amplify the basic patterns already observed. Among the household units forming small overlapping clusters of specialized tools for craft production in dimensions 1 and 2, another small subgroup with high proportions of fine-edged choppers and awls/drills is distinguished in the upper right. And household units from this set that lie at the top of the plot of dimensions 2 and 3 have the highest proportions of blades. The plot of dimensions 2 and 3 also makes the clearest distinction between household units with low-quality lithic raw material toward the lower right in this plot and high-quality raw material toward the upper left. The former goes along with high proportions of debitage and probably relates to reduction for heavy tool production, while the latter corresponds to the group of household units involved in blade production toward the bottom of the plot of dimensions 1 and 2 .

\section{Lithic Assemblages at Fushanzhuang \\ *****INSERT FIGURE 8 ABOUT HERE*****}

The most interpretable multidimensional scaling result for Fushanzhuang lithic assemblages (Figure 8) was produced from standardized Euclidean distances between all pairs of the 19 household units; three dimensions were required for an acceptably good representation of the data, and the final stress for this three-dimensional configuration was 0.115 . This multidimensional scaling result differs from that presented by Peterson (2006:147) because slightly different variable sets were used in this reanalysis for comparison with Upper Daling assemblages, but it leads to similar interpretations and conclusions.

Most of the household units cluster loosely toward the upper right in the plot of dimensions 1 and 2. This cluster appears somewhat more diffuse than the cluster including the majority of Upper Daling household units in Figure 7, but much of this appearance is attributable to the smaller number of household units in the Fushanzhuang analysis. High proportions of ground stone tools used for agriculture/woodworking identify these as households engaged primarily in food production. Complete flakes and unifacial scrapers represent the mixed light duty tool set that was also a part of the assemblages of ordinary household units in the Upper Daling scaling. Broken flakes and abraders for latestage lithic reduction are also abundant in this cluster, especially toward the right side. Also as in the Upper Daling scaling, the mixed light duty, late-stage lithic reduction, and agricultural/woodworking tool sets, while overlapping, are most abundant in different parts of the cluster. Awls/drills, flake cores, 
shatter, debitage, and tool blanks, representing miscellaneous craft production, early-stage lithic reduction, and heavy tool production are especially abundant in households at and beyond the extreme left margin of this cluster. Three of these leftmost households in the plot of dimensions 1 and 2 also have high proportions of projectile points and choppers, suggesting emphasis on hunting and heavy scraping and chopping. These varying emphases on different aspects of relatively common activities indicate some degree of productive differentiation, but the separation between these groups is not as clear as in the Upper Daling scaling.

A single household unit (F04) lies far from all others in the lower right portion of the plot of dimensions 1 and 2 because of its very high proportions of blades and blade cores. Other households with only slightly elevated proportions of blades and blade cores are found in the lower right portion of the main cluster. The blade production indicated for these households may have been an activity more strongly separated from those of ordinary households than the activities discussed above.

The plot of dimensions 1 and 3 adds detail to the basic pattern from the plot of dimensions 1 and 2. Essentially the same set of household units occurs at the left side of both plots. In this view, however, early-stage lithic reduction and miscellaneous craft production are more clearly separated from late-stage lithic reduction. This plot of dimensions 1 and 3 closely resembles the one interpreted by Peterson (2006:147); household units group in very similar ways in both. The plot of dimensions 2 and 3 is presented in Figure 8 for completeness, but it adds little to the patterns already observed.

The patterns in the Fushanzhuang lithic assemblage analysis are somewhat easier to describe than those in the Upper Daling analysis, reflecting less complicated sorting of activity emphases between households. There is clearly some degree of productive differentiation at local communities in both core zone and periphery, and thus some degree of economic interdependence between households. The median Euclidean distance between pairs of Fushanzhuang household lithic assemblages is 5.456 (with an error range for $95 \%$ confidence of 5.196-5.788). For the Upper Daling analysis, this figure is 5.680 (5.517-5.803). The statistical significance of this difference between core zone and periphery household lithic assemblages is less than that for ceramic assemblages and the magnitude of the difference is quite small. Core zone household lithic assemblages thus suggest only very slightly more productive differentiation than those of Fushanzhuang in the periphery, and the degree of productive differentiation indicated by lithics in both places seems quite small.

\section{Pottery Production and Distribution}

Another window into the operation of the Hongshan quotidian household economy is provided by ceramics. All Hongshan pottery was fired at relatively low temperatures that are easily achieved without enclosed kilns and thus would lend itself to fairly dispersed patterns of production. It has been speculated that, because of their very large size and elaborate painted decoration, the production of painted ceramic cylinders (tongxingq ) used as architectural elements in ceremonial platforms required skills acquirable only through a high level of specialization (Teng 2009; Xu 2004). But aside from possible pottery kilns excavated at Xiaoheyan (Liaoning et al. 1977) and Shangjifangyingzi (Jilin and Neimenggu 2008), there has been little direct evidence of pottery production and no investigation of patterns of distribution.

A very large sample $(n=715)$ of sherds was selected from the Upper Daling household artifact assemblages for geochemical analysis by X-ray fluorescence and X-ray diffraction (Li 2016a, 2016b). Altogether 16 of the 50 household units were chosen for sampling (six each from the Dongshanzui and Sanjia zones and four from the Erbuchi zone). Sampled households were spread broadly through all parts of the three residential zones, and represented the full diversity of household assemblages identified in the multidimensional scaling analyses. Sherd samples were selected separately from each household unit with a target sample size of 50 sherds per household unit. Within each sampled household, a stratified sampling design was used, with separate samples selected from the abundant fine-paste sherds $(n=30)$ and the scarcer coarse-paste sherds $(n=10)$ and tongxingqi sherds $(n=10)$. For the scarcer sampling strata the target number was not always achievable. All 715 were analyzed by handheld X-ray fluorescence, resulting in the identification of 12 groups based on elemental composition. A subsample of 171 sherds, representing all 12 compositional groups, was analyzed by X-ray diffraction, revealing mineralogy that is extremely homogeneous and common in the Upper Daling river valley across all 12 groups, leading to the conclusion that the raw materials for this pottery were all very local, varying in 
elemental composition but not in mineralogy. This is consistent with the observation that a small sample of sherds from Dongshanzui that were dated by thermoluminescence had radioactivity very similar to those of adjacent sediment samples, suggesting that the pottery was made locally (Feathers 2014).

All 12 compositional groups appeared at household units in all three residential zones, but five of them were very common in the northernmost zone at Erbuchi, less common in the central zone at Dongshanzui, and rare in the southernmost zone at Sanjia. Three other compositional groups were common in the south and rare in the north. And four were common at Dongshanzui and rare toward the north as well as toward the south (Li 2016a:94). This seems to represent a set of fall-off patterns of declining abundance of pottery with distance from production source units. The fall-off is visible across the $7 \mathrm{~km}$ distance covered by the residential zones in this study, and if it continued at a similar rate beyond, would suggest that pottery did not generally travel more than 10-15 km from its place of production. Such distributions, of course, can have long tails, and very small quantities of pottery undoubtedly traveled farther, but Hongshan households seem to have acquired the bulk of their pottery at fairly short distances.

No compositional group appeared in fewer than 8 of the 16 household units sampled, and 2 groups appeared in the 50 -sherd samples from every single one of the 16 household units ( $\mathrm{Li}$ 2016a:102). This means that all 12 compositional groups would almost certainly have been discovered, even if only 8 (or even fewer) households had been sampled. In the other direction it also means that even if a much larger number of households were sampled, the number of compositional groups discovered would probably not increase much at all. Twelve seems a good approximation of the number of pottery source units for the Hongshan pottery from this sector of the Upper Daling valley. These pottery source units may not have a one-for-one correspondence with pottery "producers." Multiple "producers" might have obtained raw material in the same place and used similar procedures for making pottery, resulting in the same elemental composition. At the same time, single pottery "producers" might have obtained material in different locations or used different procedures. The presence of these 12 compositional groups, however, does help pin down the degree of productive differentiation: it means that each household did not make pottery for its own use, and it means that pottery for this sector of the Upper Daling valley was not made by just one or a very small handful of workshops.

Although operating on a fairly small spatial scale, pottery distribution networks were complicated, overlapping, and non-exclusive. Only one household pottery sample out of the 16 included as few as half of the 12 compositional groups, and one yielded all 12 (Li 2016a:102). Households unfailingly acquired their pottery from multiple production source units. Since the Dongshanzui and Sanjia residential zones are in one regional-scale community and Erbuchi in another (Peterson et al. 2010, 2014a), economic interdependence clearly crossed such community boundaries. In fact, boundaries of supra-local communities are not only open as far as pottery distribution networks are concerned, they seem to pose little or no impediment to the flow of pottery. Dongshanzui and Sanjia are quite close together and within the same regional-scale community, but Dongshanzui's pottery consumption patterns resemble those of Sanjia only modestly more than those of Erbuchi, farther away and in a different supra-local community.

These conclusions about pottery distribution patterns rely on samples that include both utilitarian vessels for food preparation, serving, and storage as well as on the lone vessel form with an identifiable non-utilitarian function: the tongxingqi cylinders used as architectural decoration on platforms.

Tongxingqi were also apparently used in domestic contexts in some way because tongxingqi sherds also appear in household garbage in the Upper Daling valley, and they were thus included in the sample for geochemical analysis. Tongxingqi sherds appear in more than trivial numbers in all 12 compositional groups. While they are more abundant in the products of some compositional groups than others, no compositional group can be identified as strongly focused on their manufacture. They are more homogeneous in geochemical composition than utilitarian vessels, but only slightly (Li 2016a:157). Thus despite the impression some have that only highly trained specialists would have been able to make tongxingqi, they represent, like utilitarian pottery, only a low level of productive differentiation.

In sum, very modest productive differentiation is detectable in Hongshan pottery distribution patterns. Pottery was not made in every household, but if each of the 12 compositional groups represents one household focusing on pottery production, this would make pottery producers of roughly $5-10 \%$ of the households in the two supra-local communities. If several different households were 
involved in each of the compositional groups, then this proportion would be even higher. This is indeed productive differentiation and economic interdependence-some households did not make pottery but relied for it on other households. But it is such a low level of productive differentiation that neither tongxingqi nor utilitarian pottery would qualify for the designation of specialized production according to some definitions of craft specialization (Hirth 2006:8). These conclusions apply only to the Upper Daling valley communities in the Hongshan core zone, which we cannot compare to Fushanzhuang in the periphery in this regard since there are no geochemical data for Fushanzhuang pottery. The only serious contender for craft specialization would, then, seem to be jade carving, based on the required skill level imputed to it. Some of the carved jade included as offerings with the burials of important people is actually of rudimentary workmanship, but other pieces are of quite high quality. The only direct evidence of the mode or place of production, though, consists of a few jade spalls or other debitage from Niuheliang and the Dongjiayingzi site (Guo 1995:53; Liu and Dong 1997).

\section{Spatial Patterning within Residential Zones: Households and Neighborhoods}

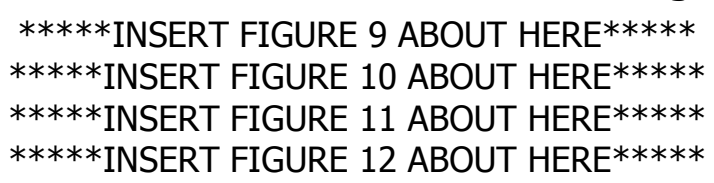

Some trends toward neighborhood-scale patterning in pottery distribution are evident at Dongshanzui, Sanjia, and Erbuchi (Li 2016a:139-147). This does not take the form of complete uniformity across households in neighborhoods with regard to their profiles of pottery procurement, but groups of two or three household units with especially similar pottery procurement profiles are often found quite close to each other. A cluster analysis shows several groups of household units with similar pottery procurement profiles (Figure 9 ). One group of three includes two closely neighboring household units (016 and 022) in a neighborhood at the extreme southeast of the Sanjia residential zone (Figure 10). The third household unit in the group (002) is not close by but at the opposite extreme of the Sanjia zone. Another group of two similar profiles is formed by the other two household units in this neighborhood for which we have pottery source data (017 and 023). In the easternmost set of household units in the Dongshanzui residential zone, all within $125 \mathrm{~m}$ of each other, all three households for which we have pottery procurement data fall in the same cluster by compositional group profiles (Figure 11). The Erbuchi residential zone is essentially a single neighborhood since all its household units are within about $200 \mathrm{~m}$ of each other. Here two adjacent household units of the four (203 and 209) are very strongly clustered together by similar pottery procurement profiles (Figure 12).

In terms of their participation in pottery distribution networks, then, neighborhoods are diverse, in that different households within them do show contrasting pottery consumption profiles. But considerably more often than one would expect, close neighbors participate in pottery distribution networks in very similar ways. Put another way, among the 16 household units represented in the geochemical analysis, there are four pairs of household units with very strongly similar pottery procurement profiles (Figure 9). Three of these four are pairs of household units located less than $100 \mathrm{~m}$ apart.

Similar elements of neighborhood structure appear patchily but unmistakably in the activity sets represented by household lithic assemblages at Dongshanzui, Sanjia, and Erbuchi as well (Figures 1012). The mixed light duty tool set identified in the multidimensional scaling analysis is strongly represented in many household units widely scattered through all three Upper Daling residential zones, just as would be expected for a tool set reflecting common daily household activities. Much the same can be said of the fine cutting tool set. These two together constitute a kind of baseline lithic assemblage for ordinary functions.

The miscellaneous craft production tool set varies from household unit to household unit, with multiple overlapping sets of specialized tools, and as might be expected is well represented in only a relatively small number of household units (six). Since proportions of these more specialized tools are higher in these six households, proportions of the mixed light duty set are lower. Of the six, two (009 and 011) pair up spatially in Sanjia only about $150 \mathrm{~m}$ from each other, and both especially emphasize 
abraders. Another trio from the six includes two immediately adjacent household units in Dongshanzui (113 and 116) and a third (108) about $200 \mathrm{~m}$ away; all three especially emphasize awls and drills.

The hunting tool set is strongly represented at only four household units. Three of them are at Sanjia, and two of these (006 and 007) are less than $50 \mathrm{~m}$ apart. The heavy scraping and chopping tool set is sometimes well represented in the same household units with hunting tools. The four household units in Sanjia emphasizing heavy scraping and chopping comprise two pairs of immediately adjacent households (012 with 013 and 022 with 023). There are also four household units emphasizing heavy scraping and chopping at Dongshanzui, three of which $(103,106$, and 107) are located within a distance of $50 \mathrm{~m}$. Another four households emphasizing heavy scraping and chopping at Erbuchi include three within a distance of $60 \mathrm{~m}(205,209$, and 210). Ten household units at Sanjia have high proportions of the early-stage lithic reduction tool set. Five of them $(003,004,005,006$, and 007) are in a group of seven household units spanning less than $200 \mathrm{~m}$, and the other five $(015,016,019,020$, and 023) are in a group of nine households spanning less than $100 \mathrm{~m}$.

In sum, close neighbors at Dongshanzui, Sanjia, and Erbuchi share both productive activity emphases and participation in pottery procurement networks often enough to suggest that neighboring households were especially closely connected to each other. These connections might reflect kinship links or other kinds of social bonds. Economic interdependence between household units was clearly not limited to the neighborhood scale. Instead, the instances of two or three neighboring household units sharing the same lithic tool sets indicate a focus on services or products that were provided to the residents of other neighborhoods where those tool sets were under-represented. Thus economic interdependence between the residents of different neighborhoods, even if slight, is indicated both by lithic assemblages and compositional analysis of pottery.

There are some indications that links embodied in the spatial proximity of households within neighborhoods also connect productive activities with social prestige. This suggestion is strongest at the southeastern extreme of Sanjia where nine household units are unusually tightly packed together (Figure 10). Seven of the nine are of high prestige, and all nine have at least one strongly represented lithic tool set in addition to the widespread mixed light duty set indicative of general daily activities in many households; most of the nine have two or three additional tool sets strongly represented. The early-stage lithic reduction, late-stage lithic reduction, and heavy tool production activities are especially emphasized. The household unit that stands out most strongly for high prestige (019), in the very center of this household group, has particularly high proportions for all three of these tool sets in addition to the mixed light duty set. Different household units in this group also had high proportions of both high- and lowquality lithic raw material. Whatever the nature of a relationship between higher social prestige, access to lithic raw material of varying kinds, and lithic tool production, these things all do converge in a remarkable way on this one neighborhood. This convergence is the strongest indication in the spatial patterning that social prestige and productive activities were related. The evidence would be consistent with the idea that higher prestige facilitated access to varied lithic raw material used in the production of a diversity of tools, especially agricultural tools and blades. This neighborhood, then, where household units of high prestige were concentrated could also have been a special source of lithic tools that were procured from the residents of this neighborhood and used by other household units in the community. $* * * * *$ INSERT FIGURE 13 ABOUT HERE*****

At Fushanzhuang, the agriculture/woodworking and mixed light duty lithic tool sets are well represented in a goodly number of households, widely scattered through the village, just as expected for what were regarded as baseline tool sets for common daily activities (Figure 13). Among other widespread activities, early-stage lithic reduction and late-stage lithic reduction tend to be emphasized in different households, as indicated in the multidimensional scaling, but both activities are also scattered broadly across the village. As in the Upper Daling valley, at Fushanzhuang the same tool sets are emphasized in neighboring household units more often than would be expected. Blade production is particularly heavily represented at three household units (F04, F09A, and F10B), all within $100 \mathrm{~m}$ of each other. Similarly the only two household units with substantial representation of the hunting tool set are only $100 \mathrm{~m}$ apart (F01 and F07). And the two household units with the strongest representation of the miscellaneous craft production tool set are also $100 \mathrm{~m}$ apart (F03 and F07). 
Indications that prestige differentiation has some relationship to productive differentiation come in the same form as at Sanjia. Three of the five high-prestige household units (F01, F03, and F06) are immediately adjacent to each other, with two additional household units (F13A and F13B) forming a neighborhood spatially set off from the rest of the village. One of these two other household units (F13A) shows a much stronger representation than any other household unit of tool sets not part of the broadly distributed common daily activities set. Two of the high-prestige households (F03 and F13A) also have high proportions of tool sets outside the common daily activities group. Altogether, more than half of the instances in the village of especially heavy emphasis on more specialized tool sets occur among these five household units. The two other high-prestige households (F13A and F13B) are also immediate neighbors, but the less usual lithic tool sets are not especially strongly represented here. Unlike Sanjia, at Fushanzhuang this spatial association between prestige and productive differentiation does not involve either early- or late-stage lithic reduction.

$* * * * *$ INSERT FIGURE 14 ABOUT HERE*****

The clearest spatial patterning of household characteristics at the neighborhood and individual household scale concerns prestige and ceremonial activities. At Dongshanzui, two household units with indicators of higher prestige are immediately adjacent to the large excavated ceremonial platform, and another is only $100 \mathrm{~m}$ away from it. At the southeastern extreme of Sanjia seven high-prestige household units form the majority of a tightly packed group of nine household units in a patch only $100 \mathrm{~m}$ across. The edge of a ceremonial platform was encountered in a test excavation here, immediately adjacent to one of the high-prestige household units. Another high-prestige household unit is located at the northwestern extreme of Sanjia, less than $100 \mathrm{~m}$ from a platform. And the only high-prestige household unit at Erbuchi is immediately adjacent to the one known platform there. Household units with high proportions of tongxingqi sherds are also found closer to platforms than household units with lower proportions of tongxingqi sherds. The consistency and statistical confidence of this pattern of spatial association between high proportions of tongxingqi sherds and higher prestige in household units on the one hand and ceremonial platforms on the other is illustrated in Figure 14.

At Fushanzhuang in the Hongshan periphery, high-prestige households are also close to the platforms, but so are some other households without indicators of very high prestige. Four small platforms are arranged at the corners of an open plaza; three of the high-prestige household units are within $100 \mathrm{~m}$ of one platform, and the other two are slightly over $100 \mathrm{~m}$ from another (Figure 12). The mean distance to the nearest platform for high-prestige household units is less than for other household units, but the difference is not as great as in the Upper Daling communities although it can be identified with a good degree of statistical confidence (Figure 14).

\section{Conclusions}

Analysis of Hongshan household assemblages and their spatial patterning is entirely consistent with broad general archaeological ideas about small Neolithic villages. These villages were mostly quite dispersed, with houses spread as much as 50-100 m apart. They can, nonetheless, be identified as coherent local communities, set off from a much more open landscape dotted with individual homesteads that sometimes clustered by twos and threes. Within the generally dispersed villages there were sometimes much more nucleated clusters of houses as close as 10-15 m from their neighbors, forming spatially definable neighborhoods. This description seems equally applicable to the core zone and the periphery.

\section{Prestige, Productive, and Wealth Differentiation in Core and Periphery}

Production of the utilitarian necessities of daily life, as well as of much more elaborate ritual items like tongxingqi, was at the household level. Both prestige and productive differentiation (Drennan and Peterson 2012:76-79) are unmistakable in the household pottery and lithic assemblages, and any degree of productive differentiation entails a similar degree of economic interdependence between households. It is important to note that both prestige and productive differentiation, while clearly in evidence, were equally clearly quite modest in scope. There is no indication of anything even remotely approaching full-time craft specialization. Indeed the modest scope of productive differentiation seen in Hongshan villages would be too minimal even to qualify for the label of specialization by some definitions. 
Costin (1991) might call it very low-intensity specialization, although there has been so much debate about defining the word "specialization" that, following Smith (2004:82), we have avoided it here in preference to "productive differentiation," conceived of as running along a continuous scale from low to high, not in presence-absence terms as a nominal variable. Nothing in the household assemblages suggests a life of luxury or a higher standard of living for the most prestigious households or those with special tool sets. This is consistent with the relatively homogeneous small size of house structures at Hongshan settlements that have been excavated, although there are no excavated data on houses for Dongshanzui, Sanjia, Erbuchi, or Fushanzhaung. Wealth differentiation (Drennan and Peterson 2012:7678) between Hongshan households is thus not recognizable at all in the household assemblages.

Median Euclidean distances were used above to show very slightly greater prestige differentiation and possibly very slightly greater productive differentiation in the core zone communities. They can also put a finer point on the comparison between these two sorts of differentiation. Median Euclidean distances between households will be greater if the number of variables they are based on is larger, so they must be divided by the number of variables ( 4 for the ceramic analysis and 19 for the lithic analysis) in order to compare them across analyses. The median Euclidean distance per variable for household ceramic assemblages in Upper Daling household assemblages is 0.627 (0.606-0.646 at $95 \%$ confidence) compared to 0.509 for Fushanzhuang (0.452-0.599 at $95 \%$ confidence). The median Euclidean distance per variable for household lithic assemblages in Upper Daling household assemblages is 0.299 (0.2910.305 for $95 \%$ confidence) compared to 0.287 ( $0.273-0.305$ for $95 \%$ confidence). Measured in this way, the prestige differentiation indicated by ceramic assemblages is stronger than the productive differentiation indicated by lithic assemblages for both core and periphery households.

At both Fushanzhuang and Sanjia there is some indication of a connection between higherprestige households and productive differentiation. This raises at least the possibility in both cases that such a connection with productive activities contributed to the enhancement of household prestige. The convergence of high prestige and particular productive activities in the tightly nucleated cluster of households at the southeast of the Sanjia residential zone is clearer than the connection between prestige and production seen at Fushanzhuang. Productive differentiation in the Sanjia village economy thus seems both slightly more strongly developed and slightly more strongly connected to social ranking than at Fushanzhuang.

Households with higher prestige in the Upper Daling communities also participated in pottery procurement networks in subtly different ways. Ordinary households seem often to have relied substantially on four or five or even more pottery source units (except for a very few who relied extremely heavily on one or two pottery source units). Households of higher prestige, however, regularly relied to a more or less equal extent on three or sometimes four pottery source units as their major suppliers. It is possible that this hints at a pattern of relationships with other households that balances breadth and depth in a distinctive way. One could imagine that higher prestige accrued to households with substantial ties to the "right" number of allies-neither too few to be effective nor too many to build strong relationships with. The distinctive pattern of pottery procurement in high-prestige household units, then, might reflect something about the broader patterns of networking that brought prestige to those households (Li 2016a:159-169).

\section{Ritual Differentiation, Ceremonial Architecture, and Elaborate Burials}

The scope of productive differentiation indicated and the degree of prestige differentiation detectable in the household assemblages, as well as the possibility of subtly different patterns of networking on the part of high-prestige households, all seem quite modest in comparison to the more dramatic social differences indicated by platform burials contrasted with simpler interments as at Baiyinchanghan and Nantaizi. Differences between the Upper Daling core zone communities, and Fushanzhuang in the periphery, while favoring the core zone, seem trivial in comparison to the differences between core zone and periphery in regard to the scale and quantity of ceremonial architecture and the elaboration of burials associated with it. Specifically at Dongshanzui, excavated ceremonial architecture centers on a raised platform with a hard-packed yellow earth surface on top of which was constructed a stone enclosure 12 by $10 \mathrm{~m}$ with three 1-m-high piles of conical stones inside. Two more stone walls bracket the enclosure on the east and west, and four small circular platforms with 
stone curbs ( $2.5 \mathrm{~m}$ in diameter) lay to the south at the entrance to this complex (Peterson et al. 2014a:7-11; Guo and Zhang 1984). A skeleton was encountered adjacent to one of these platforms, and additional burials have recently been found under the other small platforms. Carved jades, a large ceramic bowl, pottery figurine fragments, and tongxingqi sherds were found in association with the burials and elsewhere in the platform deposits. At least three more platforms were in the Sanjia residential zone within $1.5 \mathrm{~km}$ of the Dongshanzui ceremonial complex. These burials represent a level of funerary treatment unknown in the periphery, and considerably larger platforms and more impressive burials are known from other locations in the core zone (although household assemblage data are not available for any of those places). Construction of the ceremonial complex at Dongshanzui was carried out episodically, probably mostly in the middle and later part of the Hongshan period. The earliest construction on the site took the same form as a house structure, but an unusually large one, $7.4 \mathrm{~m}$ north-south by more than $2.5 \mathrm{~m}$ in its incomplete east-west dimension. If it was square, like most other such structures, it would have covered some $55 \mathrm{~m}^{2}$. Its entrance was especially elaborate, with steps leading down to the floor below ground level, and partitions dividing the interior space, blocking access to the left and right. It is most convincingly interpreted, along with other particularly large Hongshan houselike structures, as a structure not for residence but for communal gatherings of some sort.

The differences between the core zone and the periphery in regard to prestige and productive differentiation as indicated in household artifact assemblages, then, seem wholly unmatched to the differences seen between the core zone and periphery in regard to ceremonial activities and ritual differentiation in burial treatments (Drennan and Peterson 2012:77). The obviously important individuals buried under platforms did, nonetheless, have to live somewhere. The best candidates known for the households of individuals who might be given such treatment at death would be household units with assemblages indicating high prestige. This leads to the conclusion that, whatever made some individuals so important in death, they did not live very differently from anyone else. They seem to have had more prestige, but not greater wealth or a noticeably higher standard of living. They may have been connected to some of the tenuous productive differentiation that was emerging in Hongshan times; they may have used and displayed slightly finer and more elaborate pottery (and possibly other possessions); they may have socialized with others in their communities in slightly more refined ways; and they may have networked in a slightly distinctive way with their neighbors. But the aspects of village life best reflected in household artifact assemblages (emphasizing productive activities, wealth, and social prestige) do not provide any good indication of an economic or social basis for the sometimes dramatic differences in treatment between ceremonial platform burials with jade carvings on the one hand and known simple village burials in graves on the other hand. Ritual differentiation is, in and of itself, by far the strongest factor in setting some people apart from others and creating asymmetrical relationships in Hongshan villages. The supposed bundling of a unified set of social, political, productive, wealth, and ritual elements into a single integrated early-complex-society package definitely did not characterize Hongshan social organization.

\section{Leadership, Power, and Regional Integration}

We are left with the conclusion that the presumed leaders of Hongshan polities, some of whom were buried in elaborate ceremonial facilities, were special principally in a ritual realm that was little reflected in the economics and social interactions of daily life. It is worth questioning whether the important individuals in these burials, as important as they seem to have been in ritual, exercised much real political power at all. Even though the symbolic manifestations of their specialness are much more highly developed in the core zone than in the periphery, the political integration accomplished in the core zone seems only trivially larger-scale (in either demographic or spatial terms) than that of the periphery. And the regional communities known for any part of the Hongshan culture area are really quite small in scale, representing populations often in the low hundreds and occasionally in the very low thousands.

If the scale of political integration is any indicator of the projection of political power, then the supposed leaders of the core zone would seem to have wielded only trivially greater power than those of the periphery, and neither wielded very much. Archaeologists sometimes turn to mobilization of labor for construction of public architecture as an indication of political power, but the ceremonial constructions of Dongshanzui would not have required large labor forces. Based on commonly-used estimates of the labor 
required for moving earth and constructing stone walls (Erasmus 1965), a very generous estimate is that the Dongshanzui ceremonial complex would have required less than 7,000 person-days. The Dongshanzui supra-local community is estimated to have had an average population of 500-1000 during Hongshan times. If one-third of the population were available laborers, they would have invested a total of 21-42 days in the construction project. Stratigraphy indicates that the construction effort was divided into several stages at different times, meaning no more than a week or two was needed for any given episode. Alternatively a very small number of workers might have been at it for a somewhat longer time. The organizational and labor requirements of public architecture, then, provide little evidence for the projection of much power by leaders.

Even calling the supra-local regional-scale Hongshan communities "polities" may be an exaggeration of the degree of organization properly called "political." A better label might be "ritualities" (a neologism attributed by Yoffee [2005:168; Yoffee et al. 1999:265-266] to one of us)-socially cohesive, centrally focused, supra-local, territorial groupings of people whose interaction and integration revolved around ceremony, ritual, and belief more than centralized political power. The ritual differentiation reflected in platform burials with jades carved in symbolic forms seems not to have spilled over into those aspects of village interaction best reflected by household assemblages. Substantial ritual differentiation, accompanied by only slight prestige or productive differentiation and no detectable wealth differentiation, seems the rule.

\section{Households, Ritual, and Ceremony}

Household assemblages do reflect the importance of ritual and ceremony in several ways. As noted above, high-prestige households are closer to ceremonial structures, and this is especially marked in the core zone-one of the biggest differences to be observed between core and periphery communities. The artifact assemblages of Dongshanzui, Sanjia, and Erbuchi also contain much higher proportions of tongxingqi cylinders than artifact assemblages from from Fushanzhuang $(4.08 \% \mathrm{vs}$. $0.04 \%$ ) -not just in association with ceremonial platforms but also in ordinary household garbage. They may have been used in household ritual in some way as well. And this usage was clearly vastly more common in the core zone communities. Household units within $100 \mathrm{~m}$ of platforms in the Upper Daling residential zones can have assemblages in which more than $5 \%$ of the sherds are from tongxingqi. This might be attributable to proximity to places where they were used architecturally in large numbers, but smaller proportions of tonxingqi sherds occur in numerous household assemblages at considerable distances from platforms at Dongshanzui, Sanjia, and Erbuchi. Figurines in household refuse at Xinglonggou (Zhongguo 2004) do suggest nonetheless that household ritual was not entirely absent in the periphery.

There seems no way to account for an intensification of religiosity and ritual in the core zone, then, in other aspects of Hongshan life or organization. Its development may need to be understood in terms of its own internal logic and historical trajectory rather than in any demographic, political, or economic foundations or implications. This involves consideration of when during the long Hongshan period different things may have happened, and our ability to distinguish different parts of the period is limited. There are at least some radiocarbon dates for the excavated ceremonial sites of the core zone and for the excavated residential remains of the periphery. For the most part, though, these dates pertain specifically to the sites and features from which the dated samples were recovered. It is possible to identify a few earlier and later features of tongxingqi but for the most part utilitarian Hongshan pottery cannot be assigned on stylistic grounds to any particular part of the period. Radiocarbon dates from our stratigraphic tests and from other excavations, as well as thermoluminescence dates on sherds (Peterson et al. 2014:21-25) indicate that the occupation of the residential zones we studied at Dongshanzui, Sanjia, and Erbuchi spans the entire Hongshan period. The low levels of productive differentiation and even lower levels of wealth differentiation seen in the household artifact assemblages, then, suggest that at no time during the Hongshan period were these economic characteristics much developed.

The belief and ritual system that came to characterize Hongshan society so strongly may have its archaeologically visible roots in large house-like structures such as the one that underlies the later ceremonial complex at Dongshanzui. These large structures have been seen as the locations of communal activities in Hongshan villages, and this is a convincing interpretation of the one at 
Dongshanzui. Its special features, unlike those of ordinary houses, make it unlikely that this was an elite residence. The household assemblages analyzed above represent materials only about $25 \mathrm{~m}$ from this structure and none of the household possessions in these nearby assemblages suggest even high prestige, much less wealth. Since the large structure is under the middle Hongshan period ceremonial complex, it likely dates to the early part of the period, consistent with four very early radiocarbon dates for nearby occupation (Peterson et al. 2014a:41). Two additional examples of such large structures, at Xishuiquan and Baiyinchanghan in the periphery well away from the Hongshan core zone, are from early to middle Hongshan times, based on radiocarbon dates, making it plausible that the formation of communities around collective activities in these structures began early on in the core zone and spread at a somewhat later date to the periphery. Also supporting this notion of a middle Hongshan period shift in the nature and expression of religion in ritual is the apparent restriction of the use of tongxingqi to the middle and late part of the period, based on radiocarbon dates from excavations of the ceremonial structures into which they were incorporated.

By middle Hongshan times the construction of full-fledged ceremonial complexes was well underway in the core zone, as confirmed by radiocarbon dates at Dongshanzui and Niuheliang, and this may represent a shift to more formalized religious beliefs, ritual activities, and priest- or shaman-like roles filled by socially important people eventually buried with carved jades under platforms. Large house-like structures for communal activities may have continued in use as well; a $50-\mathrm{m}^{2}$ example radiocarbon dated to late Hongshan times is adjacent to more elaborate ceremonial architecture at Niuheliang Locality 1 (Liaoning 2012:45-46). These places, activities, and personae could have drawn people together into growing regional-scale "ritualities," first in the core zone and later in at least some parts of the periphery, as at Fushanzhuang. The longer tradition of this pattern in the core zone would account not only for a larger accumulation of ceremonial architecture there but also its greater elaboration and a generally more important cultural position for its most impressive concentrations at places like Niuheliang. Platform building and the full complex of ritual and belief might never have taken hold in some parts of the periphery, accounting for some supra-local communities there without evidence of ceremonial platforms (although they might have had large centrally-placed structures for communal activities like the one at Baiyinchanghan, which would only be known from extensive excavation).

\section{Hongshan Communities in Comparative Perspective}

Hongshan communities, then, as much as they fit comfortably in some ways into archaeological notions of "the Neolithic village," do not in fact show any evidence at all for several elements of the unified package of social, economic, and political changes the emergence of such villages is commonly thought to foster. Social organization and community identity revolved almost exclusively around religion and ritual, which seem to have encouraged some modest prestige differentiation but very little productive differentiation and no recognizable accumulation of wealth. Such productive differentiation as occurred was not particularly focused on goods for ritual or communal use in what has been labeled the ritual mode of production (Spielmann 2002). Exchange of utilitarian goods did link villages and "ritualities," but most goods seem not to have traveled far at all. In the realm of items of ceremonial use, tongxingqi follow the same pattern as utilitarian goods; jade might possibly be an exception since the sources of the raw material might be geographically restricted and distant, although the skills required for jade carving are not much different from those needed for making much more common ground stone tools. Niuheliang's role as major sacred place and possible pilgrimage center (Peterson et al. 2010; Drennan et al. 2017) was much more important than exchange of goods in stimulating interaction among Hongshan communities across the large Hongshan territory.

Rather than encouraging the development of greater economic interdependence, accumulation of wealth and power, and larger-scale political integration-or even the formation of larger collaborating groups through collective action-the dominant role of religion and ritual in Hongshan organization may have placed obstacles in such paths of change. The societies these patterns created represent 1500 years of fundamental social stability with a consistent and heavy emphasis on collective belief, religion, and ritual (rather than productive or wealth differentiation or strong political power) as a basis of social integration. This may sound like the notion of "theocratic chiefdoms" inherited from twentieth-century cultural evolutionary thinking, which often saw religion and ritual as the central basis of early complex 
societies. And Hongshan society does bear a resemblance to other examples that have been discussed under this heading, such as the Mesoamerican Olmec societies centered on San Lorenzo or La Venta, or Mississippian societies like Cahokia, Moundville, and others in the southeastern U.S. In contrast to Hongshan stability, these societies have been seen by some as fragile and unstable, in part because of their reliance on ritual means of integration. Ritual differentiation was indeed strongly developed in these latter societies, but they contrast sharply with Hongshan societies in the degree to which other elements of the complex society package were bundled together with it. Both Olmec and Mississippian societies show considerably greater productive, prestige, and wealth differentiation than Hongshan societies. The spatial and demographic scale of their political integration and the political power of their leaders were also considerably greater. As a consequence, Mississippian and Olmec societies may have been subject to stresses that Hongshan society escaped, and this may have contributed to Hongshan organization's longevity.

Obviously no two trajectories of social change are identical in every respect, and it is by no means our intention to argue that the Hongshan trajectory is unique. It is interesting to note, though, that in the ways described above Hongshan societies resemble several early complex societies in the Americas much more than their roughly contemporaneous Yangshao neighbors in central China, where ritual is far less conspicuous, and productive and wealth differentiation considerably more strongly developed. Our hope is that by playing off both differences and similarities to other trajectories in a comparative frame we can come to understand better the social dynamics that produced them. For now these ideas remain in the realm of comparative speculation, to be pursued by further comparative analysis. It is no accident that the speculative comparisons we are able to make for Hongshan societies feature Mesoamerica and the southeastern U.S.-two regions where our knowledge derives from a multipronged archaeology focused on households and communities that combines attention to elaborate burials and monumental architecture and public works with reconstruction of village life based on residential structures as well as systematic analysis of household artifact assemblages (e.g. Drennan 1976; Welch 1991; Santley and Hirth, eds., 1993; Wilson 2008; Knight 2016; Olson and Smith 2016; Walton and Carballo 2016).

\section{Acknowledgments}

This work was supported by National Science Foundation Awards BCS-0849519, BCS-0849758, and BCS-1444978; National Geographic Society Grant 8623-09; and the American Council of Learned Societies with funding from the Henry Luce Foundation. Institutional collaboration has involved the Liaoning Province Institute of Cultural Relics and Archaeology, Renmin University of China, the University of Hawai'i, the University of Pittsburgh, and the University of the Chinese Academy of Sciences. Permission for the field work was issued by the State Administration of Cultural Heritage.

\section{References}

Aohan Bowuguan, 2009. Aohanqi Duliyingzi Xinshiqi Shidai Yizhi Diaocha Jianbao. Neimenggu Wenwu Kaogu 2009(2), 1-12.

Borgerhoff Mulder, Monique, Samuel Bowles, Tom Hertz, Adrian Bell, Jan Beise, Greg Clark, Ila Fazzio, Michael Gurven, Kim Hill, Paul L. Hooper, William Irons, Hillard Kaplan, Donna Leonetti, Bobbi Low, Frank Marlowe, Richard McElreath, Suresh Naidu, David Nolin, Patrizio Piraino, Rob Quinlan, Eric Schniter, Rebecca Sear, Mary Shenk, Eric Alden Smith, Christopher von Rueden, and Polly Wiessner, 2009. Intergenerational Wealth Transmission and the Dynamics of Inequality in Small-Scale Societies. Science 326:682-688.

Cao, Jian'en, 2010. Neimenggu Dongnanbu Xian Qin Kaogu de Shouhuo. Paper presented at Kaoguxue de Guoqu, Xianzai he Weilai-Zhongguo yu Shijie Guoji Xueshu Yantaohui, Beijing.

Chifeng International Collaborative Archeological Research Project, 2011a. Chifeng Settlement Dataset. Comparative Archaeology Database, University of Pittsburgh. <http://www.cadb.pitt.edu>

Chifeng International Collaborative Archeological Research Project, 2011b. Settlement Patterns in the Chifeng Region. University of Pittsburgh Center for Comparative Archaeology, Pittsburgh.

Costin, Cathy Lynne, 1991. Craft Specialization: Issues in Defining, Documenting, and Explaining the Organization of Production. Archaeological Method and Theory 5:1-56. 
Diwan, Romesh, 2000. Relational Wealth and the Quality of Life. The Journal of Socio-Economics 29:305340.

Drennan, Robert D., 1976. Fábrica San José and Middle Formative Society in the Valley of Oaxaca. Memoirs of the Museum of Anthropology, University of Michigan, No. 8.

Drennan, Robert D., 2009. Statistics for Archaeologists: A Common Sense Approach. Springer, New York.

Drennan, Robert D., Lu, Xueming, Peterson, Christian E., 2017. Niuheliang and Its Place in Hongshan Society. Antiquity $91: 43-56$.

Drennan, Robert D., Peterson, Christian E., 2006. Patterned Variation in Prehistoric Chiefdoms. Proceedings of the National Academy of Sciences 103, 3960-3967.

Drennan, Robert D., Peterson, Christian E., 2012. Challenges for Comparative Study of Early Complex Societies. In: Smith, Michael E. (Ed.), The Comparative Archaeology of Complex Societies. Cambridge University Press, Cambridge, pp. 62-87.

Drennan, Robert D., Peterson, Christian E., Fox, Jake R., 2010. Degrees and Kinds of Inequality. In: Price, T. Douglas, Feinman, Gary M. (Eds.), Pathways to Power. Springer, New York, pp. 45-76.

Drennan, Robert D., Peterson, Christian E., Lu, Xueming, Zhu, Da, Hou, Shenguang, 2014. Settlement and Social Dynamics in the Upper Daling and Chifeng Regions of Northeastern China. Asian Archaeology 2014, 50-76.

Duan, Tianjing, Cheng, Jingtang, Cao, Jian'en, 2011. Hongshan Wenhua Juluo Yizhi Yanjiu de Zhongyao Faxian-2010 Nian Chifeng Weijiawopu Yizhi Kaogu Fajue de Shouhuo yu Qishi. Jilin Daxue Shehui Kexue Xuebao 51(4), 18-21.

Feathers, James L., 2014. Luminescence Dating of Ceramics from the Dongshanzui Site. In Peterson, Christian E., Lu, Xueming, Drennan, Robert D., and Zhu, Da, Upper Daling Region Settlement Dataset. Comparative Archaeology Database, University of Pittsburgh. <http://www.cadb.pitt.edu>

Guo, Dashun, 1995. Hongshan and Related Cultures. In: Nelson, Sarah M. (Ed.), The Archaeology of Northeast China: Beyond the Great Wall. Routledge, London, pp. 21-64.

Guo, Dashun, Zhang, Keju, 1984. Liaoningsheng Kazuo Xian Dongshanzui Hongshan Wenhua Jianzhu Qunzhi Fajue Jianbao. Wenwu 1984(11), 1-11.

Hirth, Kenneth G., 2006. Obsidian Craft Production in Ancient Central Mexico. University of Utah Press, Salt Lake City.

Jilin Daxue Bianjiang Kaogu Yanjiu Zhongxin, Neimenggu Zizhichu Wenwu Kaogu Yanjiusuo, 2008. Neimenggu Chifeng Shi Shangjifangyingzi Yizhi Fajue Jianbao. Kaogu 2008(1), 46-56.

Knight, Charles L.F., 2016. Variation in Residential Prismatic Blade Production and Status during the Early Classic at Palo Errado, Veracruz. Ancient Mesoamerica 27, 71-90.

$\mathrm{Li}$, Tao, 2016a. Economic Differentiation in Hongshan Core Zone Communities (Northeastern China): A Geochemical Perspective, Ph.D. dissertation, Department of Anthropology, University of Pittsburgh, Pittsburgh. <http://d-scholarship.pitt.edu/27598>

Li, Tao, 2016b. Upper Daling Region Hongshan Pottery Production Dataset. Comparative Archaeology Database, University of Pittsburgh. <http://www.cadb.pitt.edu>

Li, Xinwei, 2004. Ritual and Residential: The Bang River and Laohushan River Surveys, Aohan Banner, Chifeng City, Inner Mongolia, China. Bulletin of the Indo-Pacific Prehistory Association 24, 103-112.

Li, Xinwei, 2008. Development of Social Complexity in the Liaoxi Area, Northeast China. Archaeopress, Oxford.

Liaoning Sheng Bowuguan, Zhaowudameng Wenwu Gongzuozhan, Aohan Qi Wenhuaguan, 1977. Liaoning Aohan Qi Xiaoheyan Sanzhong Yuanshi Wenhua de Faxian. Wenwu 1977(12), 1-15.

Liaoning Sheng Wenwu Kaogu Yanjiusuo, 2012. Niuheliang Hongshan Wenhua Yizhi Fajue Baogao (1983-2003 Niandu). Wenwu Chubanshe, Beijing.

Liaoning Sheng Wenwu Kaogu Yanjiusuo, Zhongguo Renmin Daxue, 2015. 2014 Nian Niuheliang Yizhi Xitong Xing Quyu Kaogu Diaocha Yanjiu. Huaxia Kaogu 2015(3), 3-8,62.

Liu, Jinxiang, Dong, Xinlin, 1997. Yanshan Nanbei Changchung Didai Shiqian Juluo Xingtai de Chubu Yanjiu. Wenwu 1997(8), 48-56.

Liu, Li, Duncan, Neil A., Chen, Xingcan, Ji, Ping, 2016. Plant-based Subsistence Strategies and Development of Complex Societies in Neolithic Northeast China: Evidence from Grinding Stones. Journal of Archaeological Science: Reports 7, 247-261. 
Neimenggu Kaogu Yanjiusuo, Chifeng Bowuguan, 2008. Yuanbaoshan Halahaigou Xinshiqi Shidai Yizhi Fajue Baogao. Neimenggu Kaogu 2008(1), 1-19.

Neimenggu Wenwu Kaogu Yanjiusuo, 1994. Balinyouqi Youhaocun Erdaoliang Hongshan Wenhua Yizhi Fajue Jianbao. In: Wei, Jian (Ed.), Neimenggu Wenwu Kaogu Wenji, Vol. 1. Zhongguo Daibaike Jinshu Chubanshe, Beijing, pp. 96-113.

Neimenggu Wenwu Kaogu Yanjiusuo, 1997. Keshiketangqi Nantaizi Yizhi. In: Wei, Jian (Ed.), Neimenggu Wenwu Kaogu Wenji, Vol. 2. Zhongguo Daibaike Jinshu Chubanshe, Beijing, pp. 53-77.

Neimenggu Wenwu Kaogu Yanjiusuo, 2004. Baiyinchanghan: Xinshiqi Shidai Yizhi Fajue Baogao. Kexue Chubanshe, Beijing.

Nelson, Sarah M., 1996. Ideology and the Formation of an Early State in Northeast China. In: Claessen, H.J.M., Oosten, J.G. (Eds.), Ideology and the Formation of Ancient States. Brill, Leiden, pp. 153-169.

Olson, Jan Marie, Smith, Michael E., 2016. Material Expressions of Wealth and Social Class at AztecPeriod Sites in Morelos, Mexico. Ancient Mesoamerica 27, 133-147.

Peterson, Christian E., 2006. "Crafting" Hongshan Communities? Household Archaeology in the Chifeng Region of Eastern Inner Mongolia, PRC. Ph.D. Dissertation Department of Anthropology, University of Pittsburgh. <http://d-scholarship.pitt.edu/8163>

Peterson, Christian E., 2012. Fushanzhuang Community Dataset. Comparative Archaeology Database, University of Pittsburgh. <http://www.cadb. pitt.edu>

Peterson, Christian E., Drennan, Robert D., 2012. Patterned Variation in Regional Trajectories of Community Growth. In: Smith, Michael E. (Ed.), The Comparative Archaeology of Complex Societies. Cambridge University Press, Cambridge, pp. 88-137.

Peterson, Christian E., Lu, Xueming, 2013. Understanding Hongshan Period Social Dynamics. In: Underhill, Anne P. (Ed.), A Companion to Chinese Archaeology. Wiley-Blackwell, Malden, MA, pp. 5580.

Peterson, Christian E., Lu, Xueming, Drennan, Robert D., Zhu, Da, 2010. Hongshan Chiefly Communities in Neolithic Northeastern China. Proceedings of the National Academy of Sciences 107, 5756-5761.

Peterson, Christian E., Lu, Xueming, Drennan, Robert D., Zhu, Da, 2014a. Hongshan Regional Organization in the Upper Daling Valley. University of Pittsburgh Center for Comparative Archaeology, Pittsburgh.

Peterson, Christian E., Lu, Xueming, Drennan, Robert D., Zhu, Da, 2014b. Upper Daling Region Settlement Dataset. Comparative Archaeology Database, University of Pittsburgh. $<$ http://www.cadb.pitt.edu>

Peterson, Christian E., Lu, Xueming, Drennan, Robert D., Zhu, Da, 2017. Upper Daling Region Hongshan Household and Community Dataset. Comparative Archaeology Database, University of Pittsburgh. $<$ http://www.cadb.pitt.edu>

Santley, Robert S., Hirth, Kenneth G. (Eds.), 1993. Prehispanic Domestic Units in Western Mesoamerica. CRC Press, Boca Raton.

Smith, Michael E., 2004. The Archaeology of Ancient State Economies. Annual Review of Anthropology 33:73-102.

Spielmann, Katherine A., 2002. Feasting, Craft Specialization, and the Ritual Mode of Production in Smallscale Societies. American Anthropologist 104, 195-207.

Sullivan, Allan P., III, Rozen, Kenneth C., 1985. Debitage Analysis and Archaeological Interpretation. American Antiquity 50, 775-779.

Teng, Haijian, 2009. Hongshan Wenhua de Shengchan Jishu Zhuangkuang Ji Shengchanli Shuiping Shulun. Chifeng Xueyuan Xuebao (Hanwen Zhexue Shehui Kexueban) 30(4), 3-8.

Walton, David P., Carballo, David M., 2016. Lithic Economies and Community Organization at La Laguna, Tlaxcala. Ancient Mesoamerica 27, 109-132.

Welch, Paul D., 1991. Moundville's Economy. University of Alabama Press, Tuscaloosa, Alabama.

Wilson, Gregory D., 2008. The Archaeology of Everyday Life at Moundville. University of Alabama Press, Tuscaloosa, Alabama.

Xu, Zifeng, 2004. Hongshan Wenhua Jingji Xingtai Chutan. Chifeng Xueyuan Xuebao (Hanwen Zhexue Shehui Kexueban) 25(2), 5-6. 
Yoffee, Norman, 2005. Myths of the Archaic State: Evolution of the Earliest Cities, States, and Civilizations. Cambridge University Press, Cambridge.

Yoffee, Norman, Fish, Suzanne K., Milner, George R., 1999. Comunidades, Ritualities, Chiefdoms: Social Evolution in the American Southwest and Southeast. In: Neitzel, Jill E. (Ed.), Great Towns and Regional Polities in the Prehistoric American Southwest and Southeast. University of New Mexico Press, Albuquerque, NM, pp. 261-271.

Zhang, Hai, Bevan, Andrew, Guo, Dashun, 2013. The Neolithic Ceremonial Complex at Niuheliang and Wider Hongshan Landscapes in Northeastern China. Journal of World Prehistory 26, 1-24.

Zhongguo Shehui Kexueyuan Kaogu Yanjiusuo Neimenggu Di Yi Gongzuodui, 2004. Neimenggu Chifeng Shi Xinglonggou Juluo Yizhi 2002-2003 Nian de Fajue. Kaogu 2004(7), 3-8.

Zhongguo Shehui Kexueyuan Kaogu Yanjiusuo Neimenggu Gongzuodui, 1982. Chifeng Xishuiquan Hongshan Wenhua Yizhi. Kaogu Xuebao 1982(2), 183-193.

Zhongguo Shehui Kexueyuan Kaogu Yanjiusuo Neimenggu Gongzuodui, Neimenggu Zizhiqu Aohanqi Bowuguan, 2005. Neimenggu Aohanqi Bang He, Laohushan He Liuyu Xinshiqi Shidai Diaocha Jianbao. Kaogu 2005(3), 7-20. 


\section{Table 1. Variables Used in Multidimensional Scaling Analyses.}

\section{Ceramic Variables}

$\%$ Decorated Sherds. Number of Hongshan sherds with incised Z motifs, other incising, finger nail impressions, appliqué bands, or painted designs / total Hongshan sherds.

\% Fine Paste Sherds. Number of Hongshan fine paste sherds / total Hongshan sherds.

$\%$ Slipped Sherds. Number of Hongshan clay slipped sherds / total fine paste Hongshan sherds. Coarse paste Hongshan sherds are not slipped.

$\%$ Serving Vessels. Number of Hongshan sherds from serving vessels ( $b o$, pen, and $b e l$ ) / total Hongshan sherds from identifiable vessel forms (bo, pen, and bei, plus guan, hu, and weng).

\section{Lithic Artifact Variables}

$\%$ Good Raw Materials. Number of flaked and ground stone tools of high quality raw materials / total flaked and ground stone tools. (Good raw materials include siliceous cherts and diorites in contrast to mudstones, sandstone, and quartzite.)

$\%$ Ground Stone Tools. Number of ground stone tools / total flaked and ground stone tools.

$\%$ Tool Blanks and Preforms. Number of unfinished tools (blanks or preforms) / total flaked and ground stone tools.

$\%$ Abraders. Number of grooved abraders (for making ground stone tools) / total flaked and ground stone tools.

$\%$ Awls and Drills. Number of flaked stone awls and drills / total flaked and ground stone tools.

$\%$ Axes and Adzes. Number of ground stone axes and adzes / total flaked and ground stone tools.

\% Chopping Tools. Number of large flaked chopping tools / total flaked and ground stone tools.

$\%$ Unifacial Scrapers. Number of flaked unifacial scrapers / total flaked and ground stone tools.

$\%$ Projectile Points. Number of flaked projectile points / total flaked and ground stone tools.

$\%$ Blade Cores. Number of blade cores / total flaked and ground stone tools.

$\%$ Retouched Blades. Number of retouched blades / total flaked and ground stone tools.

\% Flake Cores. Number of flake cores / total flaked and ground stone tools.

$\%$ Retouched Flakes. Number of retouched flakes / total flaked and ground stone tools.

$\%$ Complete Unretouched Flakes. Number of complete unretouched flakes / total debitage (complete and broken flakes, flake fragments, and shatter).

$\%$ Broken Unretouched Flakes. Number of broken unretouched flakes / total debitage (complete and broken flakes, flake fragments, and shatter).

$\%$ Shatter. Number of pieces of lithic shatter (i.e. debris) / total debitage (complete and broken flakes, flake fragments, and shatter).

Average Debitage Weight. Total weight of debitage in grams / total count of debitage (complete and broken flakes, flake fragments, and shatter).

$\%$ Acute Edge Angles. Number of flaked scrapers, retouched blades, and flakes with acute edge angles $\left(25-44^{\circ}\right) /$ total flaked and ground stone tools.

$\%$ Obtuse Edge Angles. Number of flaked scrapers, retouched blades, and flakes with obtuse edge angles $\left(45-65^{\circ}\right) /$ total flaked and ground stone tools.

Notes: The lithic artifact category "tools" does not include shatter or unretouched flakes and blades. Debitage categories used (complete and broken flakes, flake fragments, and shatter) conform to Sullivan and Rozen's (1985) typology. 


\section{Figure Captions}

Figure 1. Regions and sites mentioned in the text.

Figure 2. Typical Hongshan house structures excavated at four sites (left) and a house-like structure probably for communal activities (right). Gray areas are hearths; other features within the Xishuiquan structure are pits. (After Neimenggu 2004:379-380, 1997:57, 1994:96-97; Neimenggu and Chifeng 2008:8; Zhongguo 1982:184-185.)

Figure 3. Locations of the three Hongshan residential zones in the Upper Daling valley survey area. Pullouts show the configurations of surface collection grids mapped at larger scale in figures $10-13$.

Figure 4. A hot spot of high-density surface sherds indicated by pin-flags (toward the right rear) contrasting with a much lower-density area (foreground) in the Erbuchi residential zone.

Figure 5. Multidimensional scaling configuration of ceramic assemblages from household units at Sanjia (001-023), Dongshanzui (101-117), and Erbuchi (201-210).

Figure 6. Multidimensional scaling configuration of ceramic assemblages from household units at Fushanzhuang.

Figure 7. Multidimensional scaling configuration of lithic assemblages from household units at Sanjia (001-023), Dongshanzui (101-117), and Erbuchi (201-210).

Figure 8. Multidimensional scaling configuration of lithic assemblages from household units at Fushanzhuang.

Figure 9. Hierarchical clustering of ceramic procurement profiles for household units at Sanjia (001-023), Dongshanzui (101-117), and Erbuchi (201-210). (After Li 2016a:147.)

Figure 10. Distribution of household units in the Sanjia residential zone with the characteristics of their artifact assemblages. A dynamic version of this figure is available online (Peterson et al. 2017).

Figure 11. Distribution of household units in the Dongshanzui residential zone with the characteristics of their artifact assemblages. A dynamic version of this figure is available online (Peterson et al. 2017).

Figure 12. Distribution of household units in the Erbuchi residential zone with the characteristics of their artifact assemblages. A dynamic version of this figure is available online (Peterson et al. 2017).

Figure 13. Distribution of household units at Fushanzhuang with the characteristics of their artifact assemblages. A dynamic version of this figure is available online (Peterson et al. 2017).

Figure 14. Mean distances to the nearest ceremonial platform compared between higher and lower prestige household units in Upper Daling residential zones and at Fushanzhuang and between household units with higher and lower proportions of tongxingqi cylinders in Upper Daling residential zones. 


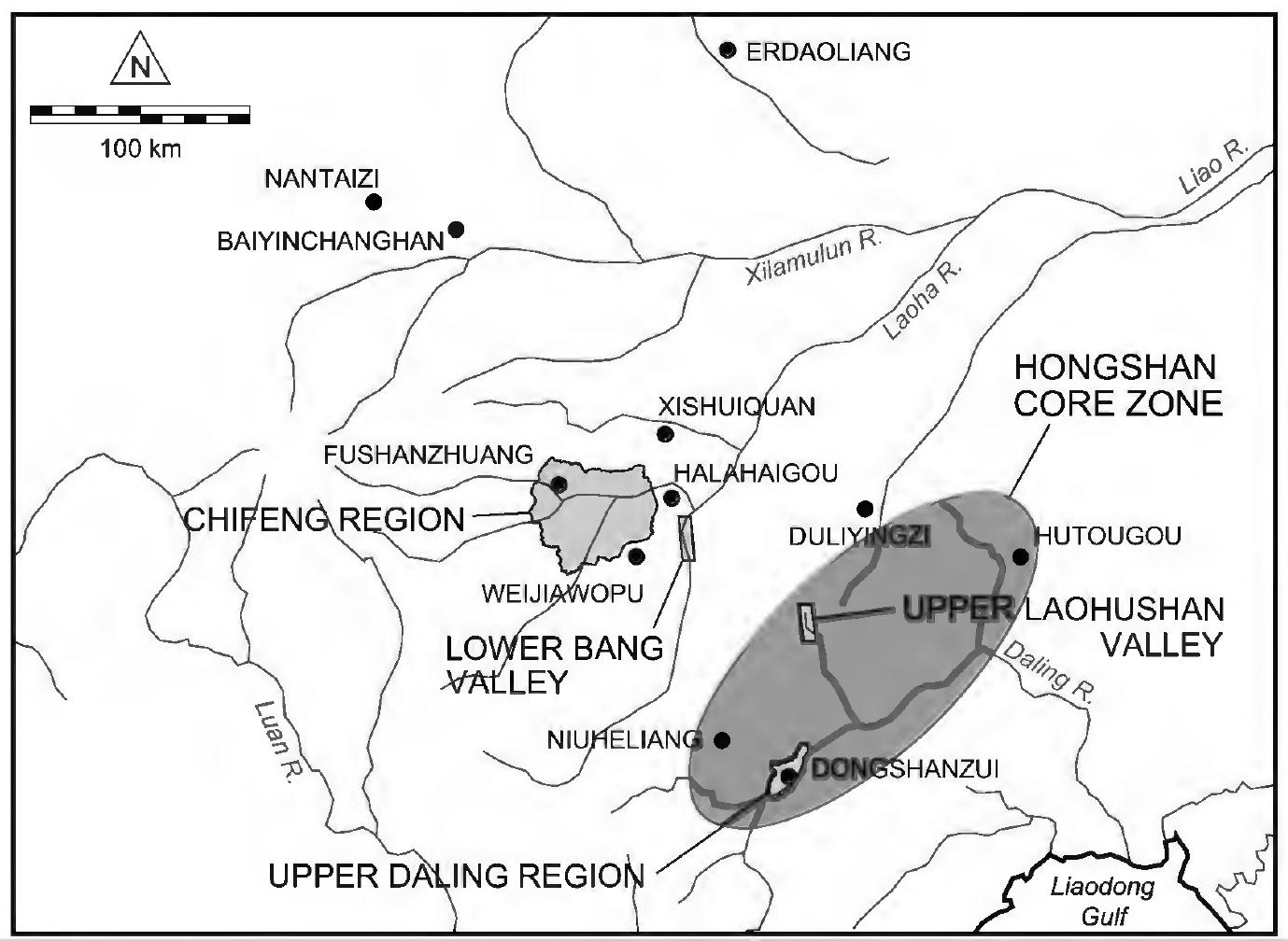




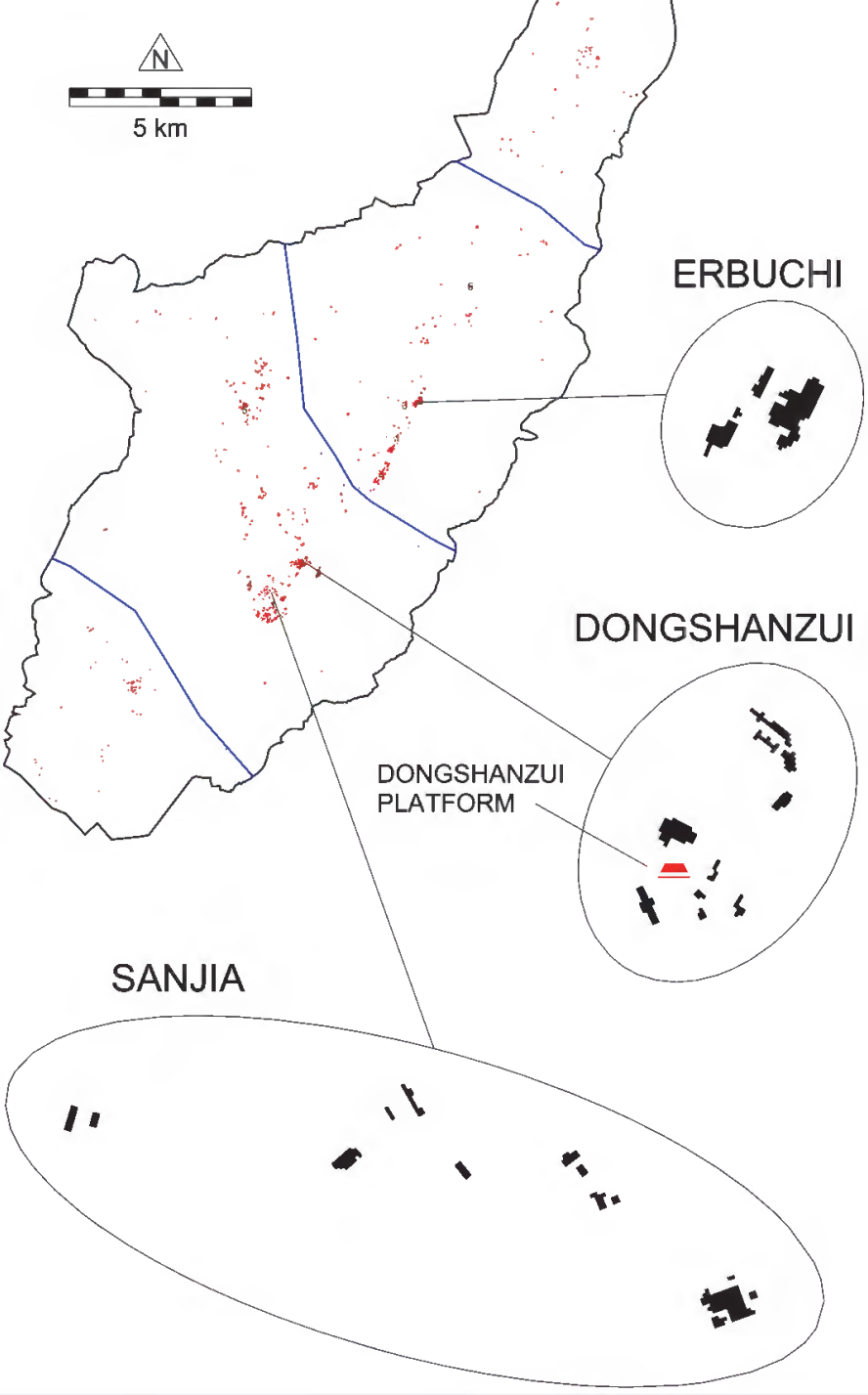




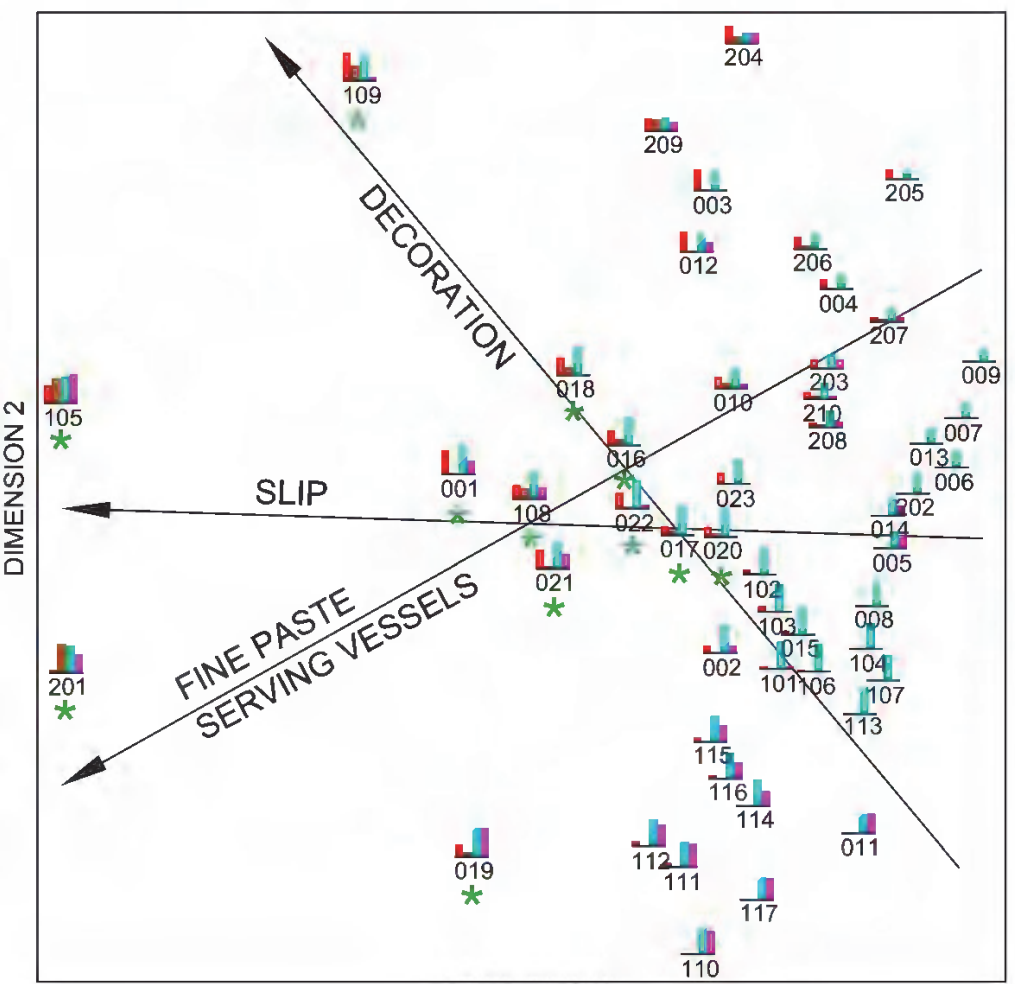

$\%$ SHERDS

108 HOUSEHOLD UNIT NO.

* HIGH PRESTIGE

ICON BARS:

- DECORATION

I SLIP

1 FINE PASTE

- SERVING VESSELS 


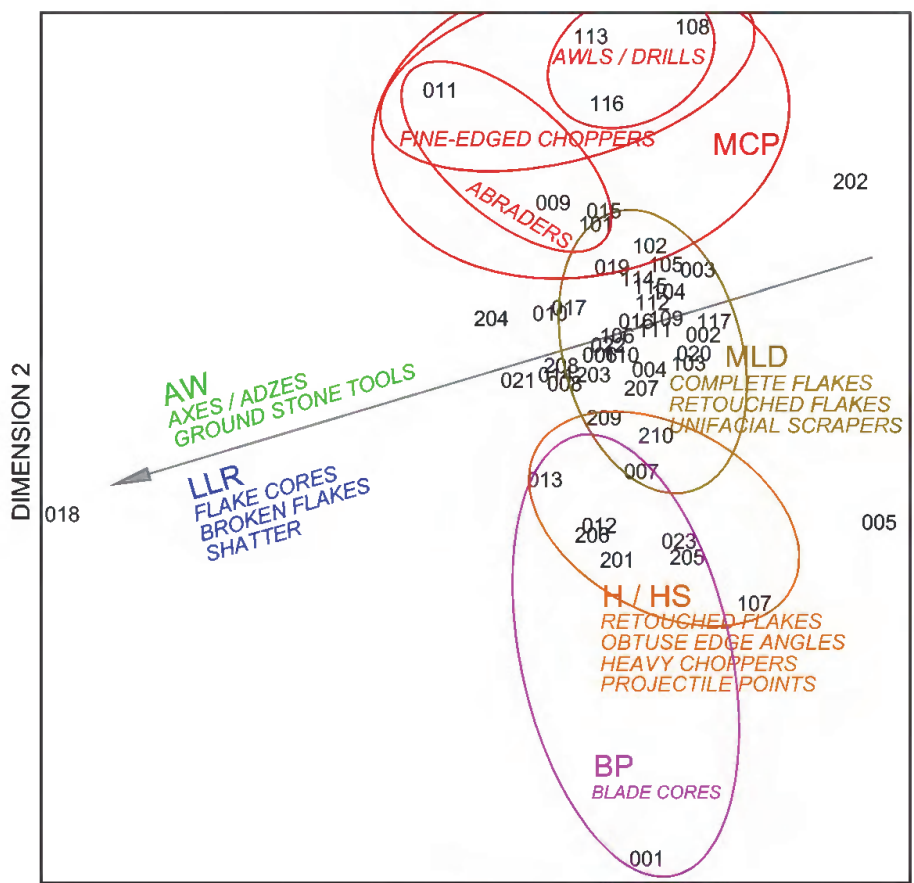

DIMENSION 1

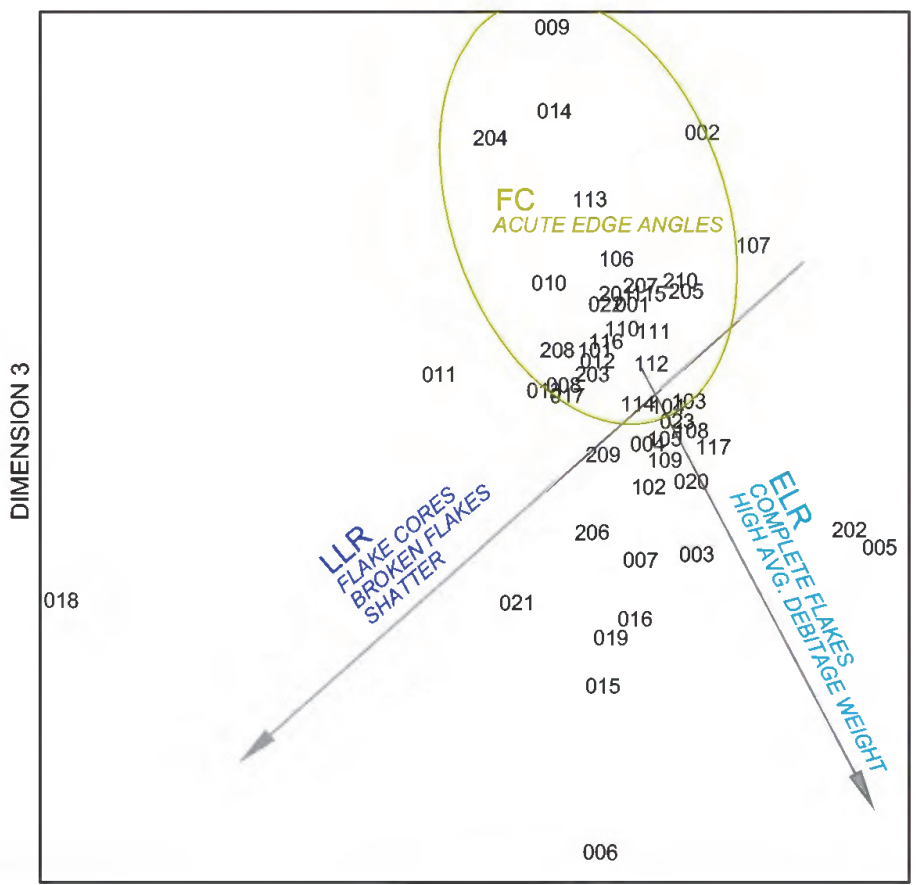

DIMENSION 1
MCP MISC. CRAFT PRODUCTION

FC FINE CUTTING

MLD MIXED LIGHT DUTY

HS HEAVY SCRAPING

AW AGRICULTURENOODWORKING

H HUNTING

ELR EARLY LITHIC REDUCTION

LLR LATE LITHIC REDUCTION

BP BLADE PRODUCTION

HTP HEAVY TOOL PRODUCTION

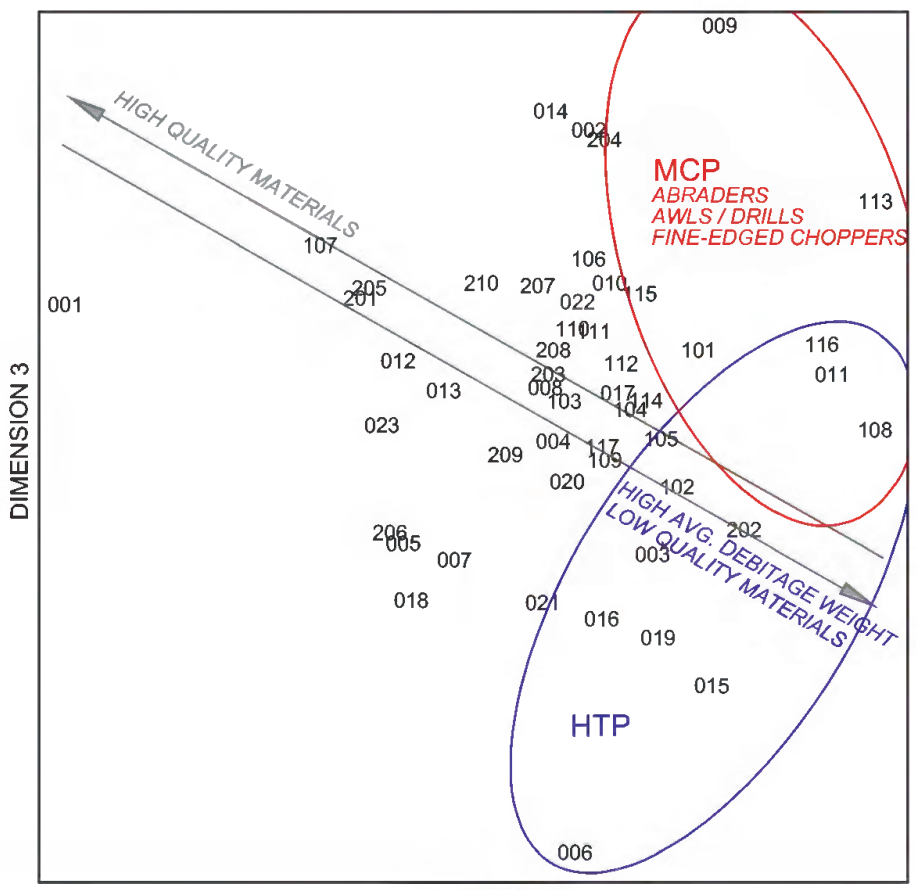




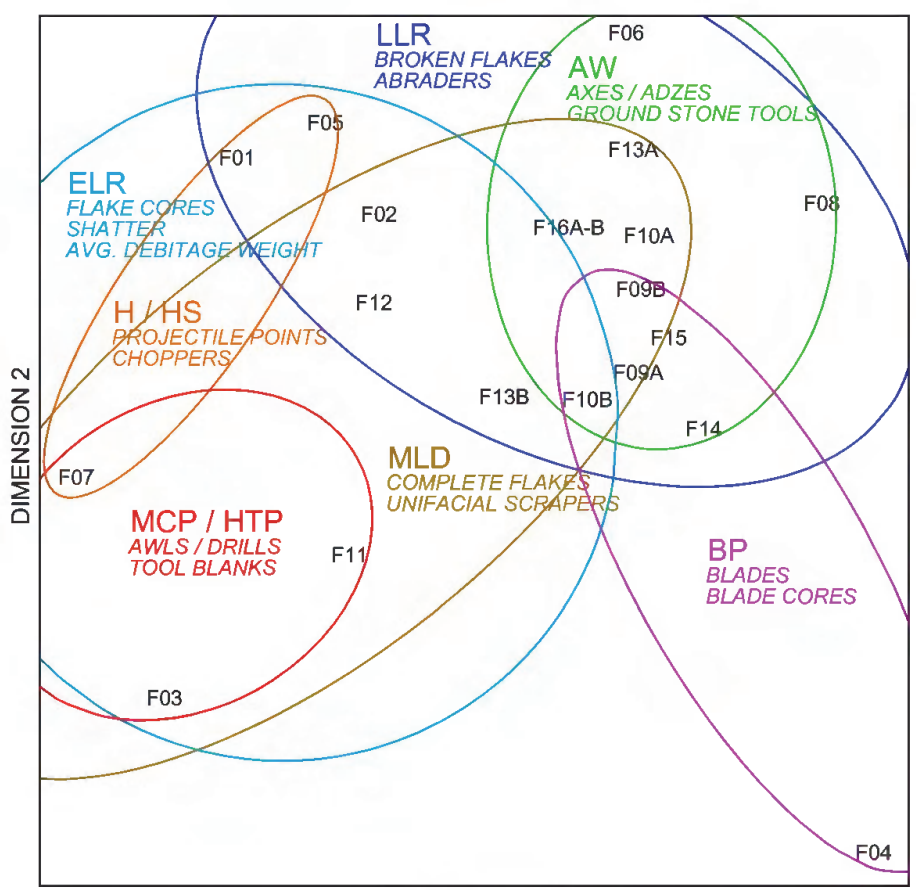

DIMENSION 1

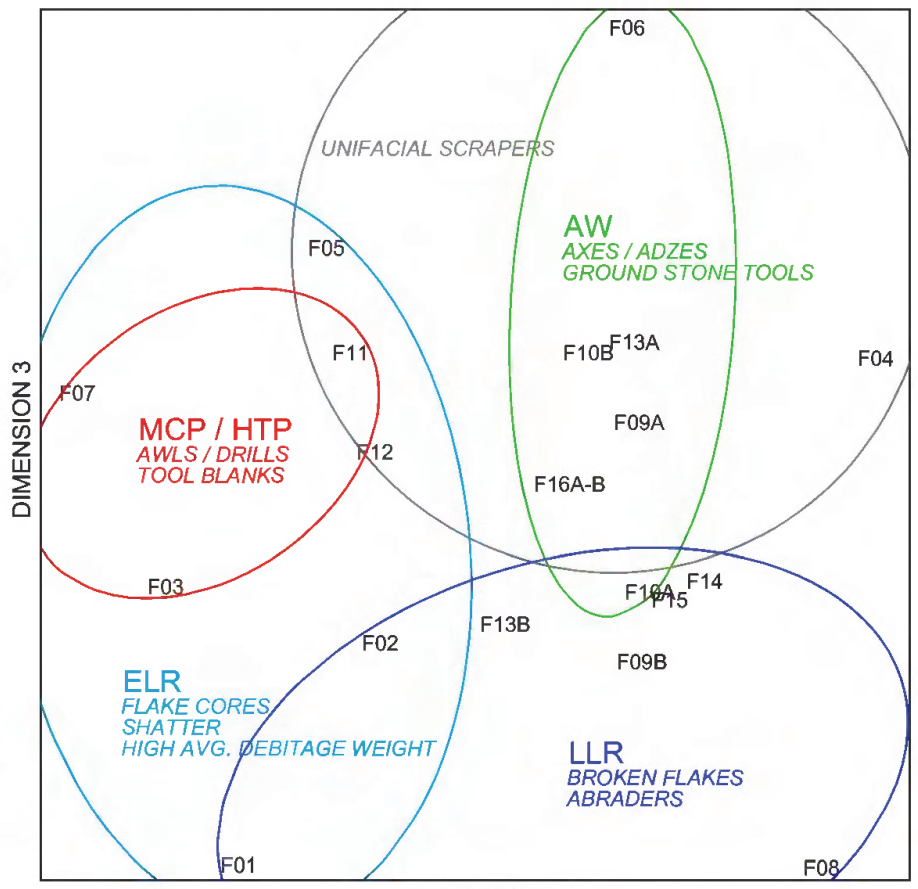

DIMENSION 1
MCP MISC. CRAFT PRODUCTION

FC FINE CUTTING

MLD MIXED LIGHT DUTY

HS HEAVY SCRAPING

AW AGRICULTUREMOODWORKING

H HUNTING

ELR EARLY LITHIC REDUCTION

LLR LATE LITHIC REDUCTION

BP BLADE PRODUCTION

HTP HEAVY TOOL PRODUCTION

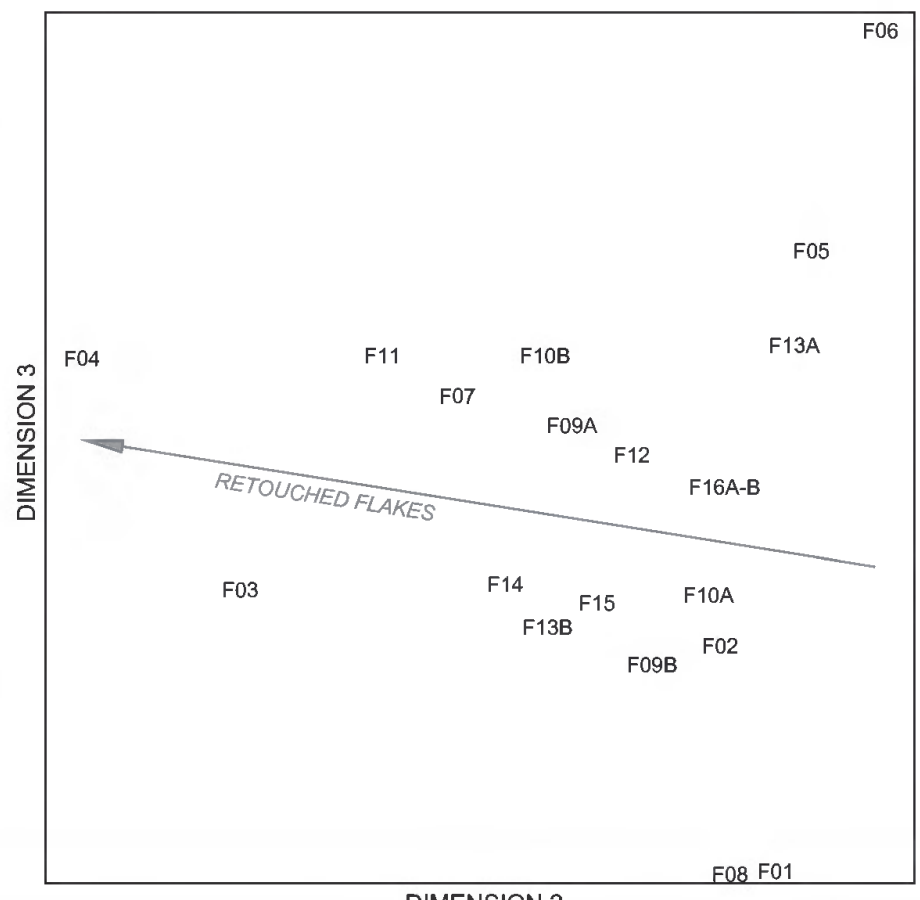


016

| II | 022

|. 002

|1. 101

I. 010

11. 109

I. 017

LلI 023

110

116
L. L. 112

I.

203

|ل 208

201

103 


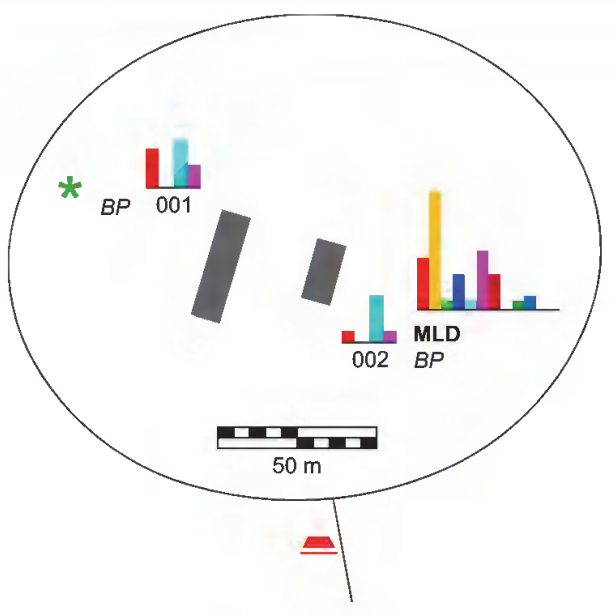

*

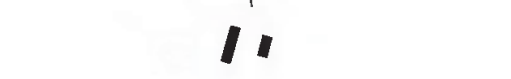

11
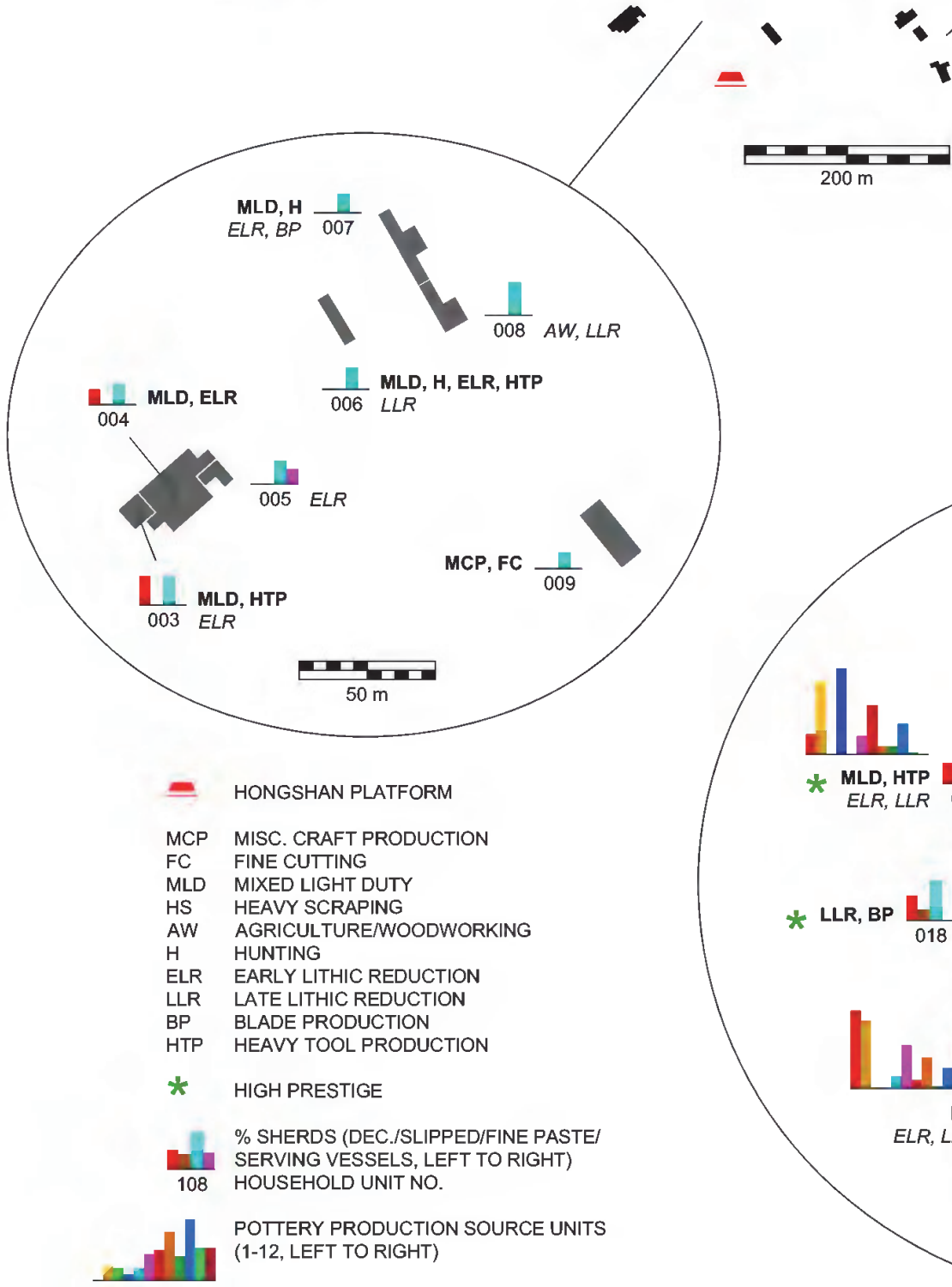

1 



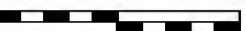

$200 \mathrm{~m}$
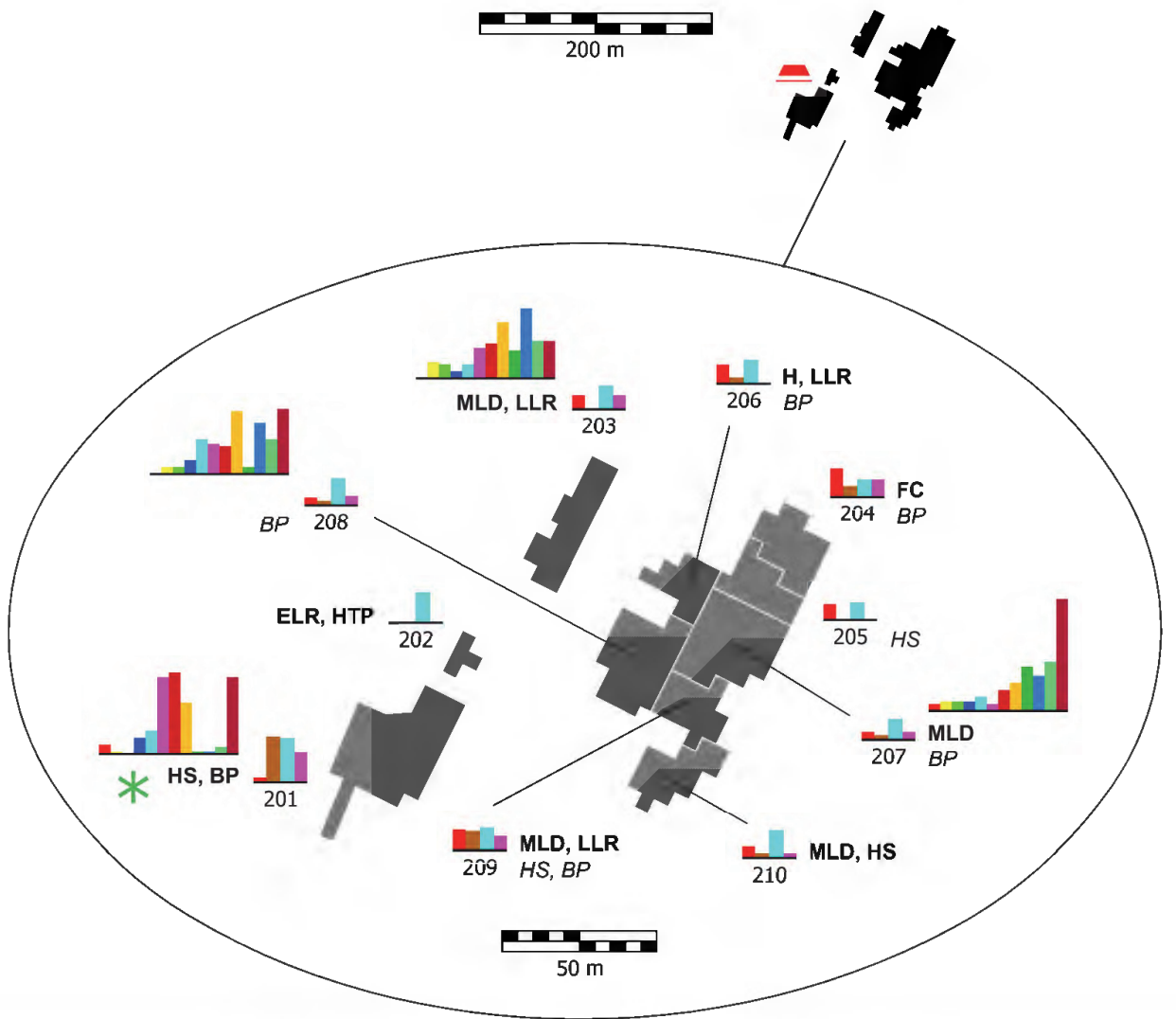

E HONGSHAN PLATFORM

MCP MISC. CRAFT PRODUCTION

FC FINE CUTTING

MLD MIXED LIGHT DUTY

HS HEAVY SCRAPING

AW AGRICULTURE/WOODWORKING

H HUNTING

ELR EARLY LITHIC REDUCTION

LLR LATE LITHIC REDUCTION

BP BLADE PRODUCTION

HTP HEAVY TOOL PRODUCTION

* HIGH PRESTIGE

$\%$ SHERDS (DEC./SLIPPED/FINE PASTE/ SERVING VESSELS, LEFT TO RIGHT)

106 HOUSEHOLD UNIT NO.

POTTERY PRODUCTION SOURCE UNITS (1-12, LEFT TO RIGHT) 


\section{EONGSHAN PLATFORM}

MCP MISC. CRAFT PRODUCTION

FC FINE CUTTING

MLD MIXED LIGHT DUTY

HS HEAVY SCRAPING

AW AGRICULTURE/WOODWORKING

H HUNTING

ELR EARLY LITHIC REDUCTION

UR LATE LITHIC REDUCTION

BP BLADE PRODUCTION

HTP HEAVY TOOL PRODUCTION

* HIGH PRESTIGE

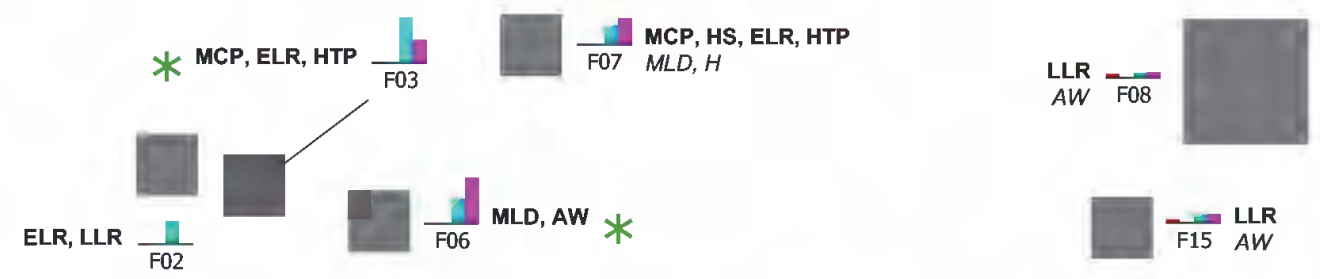

$\%$ SHERDS (DEC./SLIPPED/FINE PASTE/

SERVING VESSELS, LEFT TO RIGHT)

108 HOUSEHOLD UNIT NO.

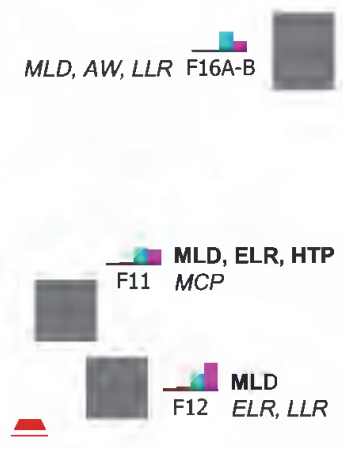

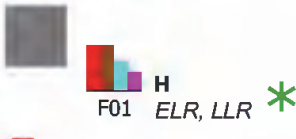

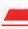
$\begin{array}{rr}\text { BP } & \\ M L D, L L R & \text { F09A }\end{array}$

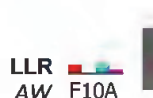

F09B LLR

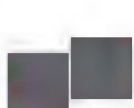

ELR, BP F10B MLD, AW

MLD

2 ELR, LLR 
MEAN DISTANCE TO NEAREST PLATFORM (m)

ALL HOUSEHOLDS

o

$\overrightarrow{8}$

HIGH PRESTIGE LOW PRESTIGE

MANY TONGXINGQI FEW TONGXINGQI ALL HOUSEHOLDS HIGH PRESTIGE LOW PRESTIGE

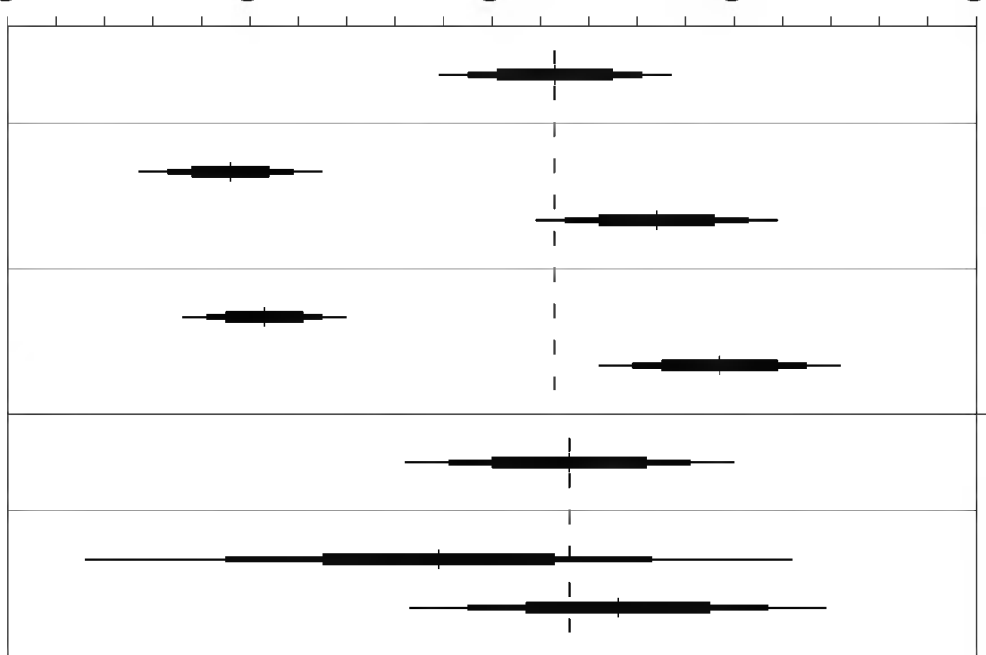


